UNIVERSIDADE DE SÃO PAULO

FACULDADE DE ODONTOLOGIA

\title{
ESTUDO DAS TENSÕES EM DENTE RESTAURADO COM COROA METALOCERÂMICA E DOIS FORMATOS DE RETENTORES INTRA-RADICULARES. \\ - MÉTODO DOS ELEMENTOS FINITOS
}

ISAAC JOSÉ PEIXOTO BATINGA DA ROCHA

Tese apresentada à Faculdade de Odontologia da Universidade de São Paulo, para concorrer ao título de Doutor, pelo curso de Pós-Graduação em Odontologia Área de Concentração: Prótese Dentária

SÃO PAULO

2000 
UNIVERSIDADE DE SÃO PAULO

FACULDADE DE ODONTOLOGIA

\section{ESTUDO DAS TENSÕES EM DENTE RESTAURADO COM COROA METALOCERÂMICA E DOIS FORMATOS DE RETENTORES INTRA-RADICULARES. \\ - MÉTODO DOS ELEMENTOS FINITOS}

ISAAC JOSÉ PEIXOTO BATINGA DA ROCHA

Tese apresentada à Faculdade de Odontologia da Universidade de São Paulo, para concorrer ao título de Doutor, pelo curso de Pós-Graduação em Odontologia Área de Concentração: Prótese Dentária Orientador: Prof. Dr. MATSUYOSHI MORI

SÃO PAULO 2000 


\section{DEDICATÓRIA}

Aos meus pais,

José Batinga e Lyrss Maria

À minha esposa, Izabela

À minha avó, Maria Lyrss

Aos meus tios,

Murilo e Maria Teresa 


\section{AGRADECIMENTOS}

Ao meu orientador, Prof. Matsuyoshi Mori, pela amizade, paciência e incentivo na minha vida profissional.

Ao doutorando Jorge Antônio Javier Saldivar Bocangel, pela paciência e dedicação no processamento dos modelos matemáticos.

Ao Prof. Saito, pela oportunidade e confiança depositadas.

À Aiko Takahashi Mori, pela colaboração e paciência e a Emerson Nakao e Carla Rumi Hanada pela ajuda na revisão deste trabalho.

Às secretárias do Departamento de Prótese Dentária, Sandra, Regina, Valdinéia e Cora e da Seção de Pós-Graduação, Cátia, Emília e Nair, meus sinceros agradecimentos.

Aos funcionários da FOUSP, pela colaboração e pelo carinho.

À todos aqueles que, de alguma forma, colaboraram para a execução deste trabalho. 


\section{SUMÁRIO}

p.

\section{RESUMO}

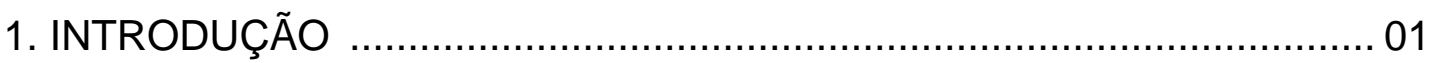

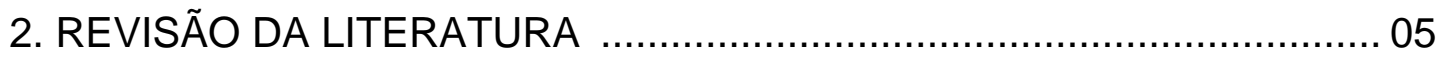

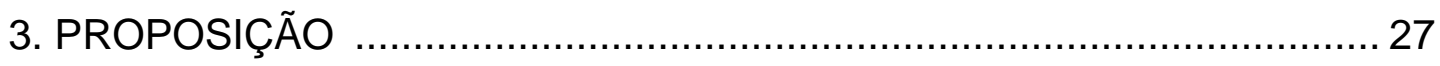

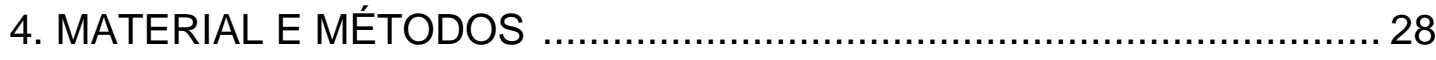

5. ANALISE E DISCUSSÃO DOS RESULTADOS ..................................... 43

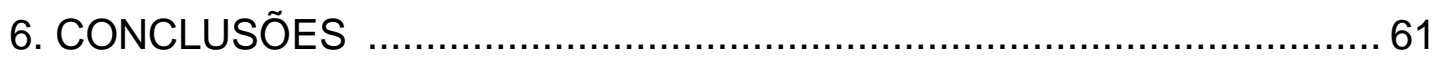

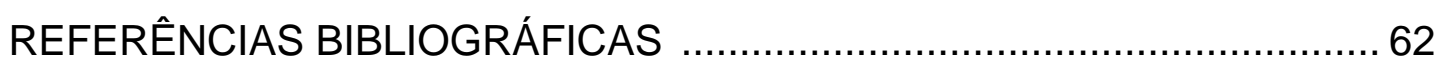

SUMMARY 


\section{RESUMO}

\section{ESTUDO DAS TENSÕES EM DENTE RESTAURADO COM COROA METALOCERÂMICA E DOIS FORMATOS DE RETENTORES INTRA-RADICULARES. - MÉTODO DOS ELEMENTOS FINITOS}

O estudo comparativo da distribuição de tensões de von Mises em dente endodonticamente tratado, com dois formatos de retentores intra-radiculares, pré-fabricado cilíndrico/escalonado e fundido cônico, foi realizado pelo método dos elementos finitos em modelos tridimensionais de caninos superiores com geometria axi-simétrica e restaurados com coroas metalocerâmicas, aplicando-se uma carga oblíqua de $100 \mathrm{~N}$ com $45^{\circ}$ de inclinação em relação ao seu longo eixo. Os resultados indicaram uma discreta diferença nos dois modelos (formatos) de retentores. O pino escalonado neutralizou mais as cargas no sentido corono-apical e no pino cônico ficou evidenciado o efeito de cunha. 


\section{INTRODUÇÃO}

A odontologia restauradora atual atravessa uma fase de utilização de novos materiais e técnicas, que objetivam a diminuição de tempo e etapas clínicas, visando a um tratamento mais rápido e eficaz.

O elemento dental, quando perde sua porção coronária, seja por cárie ou fratura, normalmente é restaurado, utilizando-se um retentor intraradicular e uma prótese unitária que restabeleçam a estética e a função .

Os retentores intra-radiculares são utilizados na restauração de dentes tratados endodonticamente, suportes de próteses parciais fixas, não só para recuperar as estruturas dentárias perdidas, mas também para servir como um reforço para dentes tratados endodonticamente. (Sheets, 1970; Hirchfeld \& Stern, 1972; Kantor \& Pines, 1977; Davy et al.,1981)

A técnica de preparo para confecção do retentor intra-radicular deve obedecer a certos princípios, que protejam o remanescente radicular da concentração de tensões, podendo levar a trincas ou fraturas da raiz, quando em função. Um maior comprimento do pino contribuirá para distribuir as tensões sobre uma maior área da raiz, melhorando sua resistência e aumentando sua retenção (Mckerracher,1981). Deve-se deixar cerca de 3 a $5 \mathrm{~mm}$ de material obturador na região apical, para se manter o selamento 
obtido no tratamento endodôntico (Colman,1979 e Deutsch et al., 1997). O máximo de estrutura dental deve ser preservada no preparo do conduto, sendo suficiente a remoção do material obturador, além das saliências e reentrâncias de sua anatomia interna (Trabert et al.,1978).

Enquanto para alguns autores como Cailleteau et al., (1992) e Assif et al., (1993), os retentores intra-radiculares aumentam os riscos de fratura de um dente com tratamento endodôntico, para outros, como Kantor \& Pines (1977); Davy et al. (1981) e Pienisnard et al. (1995), todos os dentes tratados endodonticamente deveriam receber um reforço radicular.

Estudos mais recentes demonstram que a resistência do dente tratado endodonticamente está diretamente relacionada com a quantidade e a qualidade do tecido dental remanescente. Outro fator importante na resistência do dente tratado endodonticamente é o efeito cinta, ou o abraçamento de estrutura dental em torno do retentor intra-radicular, que se consegue, preservando-se de 1,5 a 2,0 mm de estrutura dentária em torno da região cervical do núcleo (Morgano, 1996 e Morgano \& Brackett, 1999), o mesmo encontrado por Isidor et al.,1999, que encontraram melhores propriedades de retenção do pino e maior resistência da raiz.

Existe a preocupação em Ko et al., 1992; Mori, 1994; Pierrisnardt et al., 1994 (a e b); Pierrisnard et al., 1995; Veiga, 1996; Holmes et al., 1996; Deutsch et al., 1997 e Saldivar Bocangel, 1997, com a transmissão e dissipação de tensões em um dente tratado endodonticamente quando este recebe um rententor intra-radicular. Dependendo do formato dos retentores intra-radiculares, pode-se ter uma melhor distribuição de tensões sobre o 
remanescente dental. Para Henry (1977) e Spangler (1980), o formato cilíndrico parece distribuir melhor as tensões, e o formato cônico cria um efeito de cunha que pode levar à fratura da raiz.

Apesar de muitos estudos teóricos terem sido feitos com retentores intra-radiculares pré-fabricados, faltam testes de longevidade, pois, clinicamente, quando esses pinos são usados como retentores intraradiculares de próteses parciais fixas, estes parecem falhar, principalmente na interface material de preenchimento e face interna da coroa. Isso parece estar de acordo com o trabalho de Vasconcelos (1998), que comparou a utilização de retentores intra-radiculares pré-fabricados mais núcleos de preenchimento em resina composta a retentores intra-radiculares fundidos, concluindo que estes foram melhores quanto à distribuição de tensões.

Muitos trabalhos têm sido realizados para analisar a distribuição de tensões no dente tratado endodonticamente e restaurado com retentores intra-radiculares. O método de análise fotoelástica tem sido utilizado, porém, não permite a construção de um modelo com características próprias das estruturas.

O método de elementos finitos, intrduzido por Turner et al. (1956), em modelos tridimensionais, é o mais avançado e eficaz procedimento de análise de tensões, deformações e deslocamentos. Ele vem revolucionando diversas formas de pesquisa, sendo hoje uma metodologia bastante eficiente, fiel e segura.

Na busca de uma técnica rápida e eficiente, resolveu-se estudar uma nova conformação de retentor intra-radicular pré-fabricado que não 
necessita de preenchimento na porção coronária, uma vez que o núcleo apresenta um volume suficiente de metal para ser preparado, e o pino possui formato cilíndrico e escalonado, que se supõe transmitir melhor as tensões recebidas, durante o ciclo mastigatório, ao remanescente dental. 


\section{REVISÃO DA LITERATURA}

A restauração do dente tratado endodonticamente requer cuidados especiais, razão porque vem sendo objeto de discussão e pesquisa por muitos anos. Uma técnica tradicionalmente utilizada é a confecção de retentores intra-radiculares fundidos. A colocação destes retentores intraradiculares, inicialmente, objetivava a retenção para uma futura restauração protética.

O objetivo da revisão da literatura é mostrar a preocupação dos autores com o desenho, a técnica e os materiais utilizados para confecção do retentor intra-radicular. Tendo isso como afirmação, a revisão da literatura foi dividida em trabalhos que analisam os princípios de preparo do retentor intra- radicular e trabalhos que avaliam a resistência e as tensões no dente tratado endodonticamente.

\section{Princípios de preparo dos retentores intra-radiculares}

A utilização do remanescente radicular, para servir como retenção para uma futura restauração da porção coronária, já era indicada por Harris em 1871, que sem explicação científica, recomendava a extirpação do 
nervo, proporcionando acesso ao canal, onde o "pivot" seria colocado, com o pino construído em madeira.

Em 1965, Greenwald afirmou que o comprimento do pino do retentor intra-radicular deveria apresentar, no mínimo, a relação de 1:1 entre o seu comprimento e o comprimento total da coroa.

A importância de se planejar a construção de um retentor intraradicular foi mostrado por Rosenberg \& Antonoff (1971), que também indicaram a relação de 1:1 entre o comprimento da coroa e do pino, tomando-se o cuidado de não remover o selamento endodôntico do terço apical da raiz. Recomendaram pinos que não fossem largos, pois levariam ao enfraquecimento da raiz, o que poderia provocar fraturas mesmo durante a cimentação. Recomendaram, também, que, nos dentes superiores, o alargamento do canal radicular fosse maior na parede palatina e nos dentes inferiores, às custas da parede vestibular, aumentando a resistência do remanescente radicular, durante os esforços mastigatórios.

Avaliando a literatura existente sobre os retentores intra-radiculares, Stern \& Hirschfeld (1973) demonstraram a preocupação, principalmente, com a forma de retenção dos pinos, exemplificando a recomendação de se colocar dois ou mais pinos curtos como retentores para dentes multirradiculares. Esses procedimentos promoveriam retenção, porém sem a preocupação com suporte ósseo. Para os autores, o pino ideal deveria seguir a forma anatômica da raiz, evitando a sua perfuração.

Em uma revista de literatura, Abdullah \& Mohamed (1974) encontraram que o pino deveria possuir, pelo menos, o comprimento da 
coroa ou 4 a 5 mm além desse comprimento ou 2/3 do comprimento da raiz, ou em caso de raiz curta, $4 / 5$ do seu comprimento. O diâmetro do pino deveria ser pequeno para não enfraquecer a estrutura dental. Para canais divergentes, esses autores indicaram a utilização de retentores bipartidos, em vez de um alargamento maior do remanescente para buscar paralelismo entre as paredes dos canais.

Colman (1979) acreditava que as indicações para o uso de retentores intra-radiculares seriam, reforço para dentes tratados endodonticamente e retenção para uma prótese, que restaure sua porção coronária perdida, quando um dente tratado endodonticamente seja suporte de uma prótese fixa ou removível. Um princípio aceitável para construção do retentor intraradicular seria que o pino tivesse no mínimo o comprimento da coroa clínica, sendo mantido pelo menos $3 \mathrm{~mm}$ de guta - percha para garantir o selamento do tratamento endodôntico.

Analisando o desenho dos retentores intra-radiculares, Spangler (1980) considerou desvantajosa a forma cônica em pinos, por oferecer menor resistência à tração e por ter efeito de cunha. Qualquer imperfeição na fundição ou pressão excessiva no ápice poderiam conduzir a fratura do dente, ressaltando também que, a quantidade de dentina ao redor da porção apical do pino deveria ser adequadamente mantida.

Para Mckerracher (1981), o que permitiria uma maior retenção e uma melhor distribuição das tensões na raiz seria o comprimento do pino. Este, quando longo, oferece uma maior área de contato com a dentina, 
melhorando a distribuição de forças, reduzindo assim o risco de uma fratura vertical.

Turner em 1982, estudando as possíveis causas dos insucessos das restaurações de dentes tratados endodonticamente, encontrou que as principais variáveis são: o tipo de retentor intra-radicular; os métodos de reconstrução e a técnica de cimentação. A maior causa de falha observada foi o deslocamento do retentor da raiz, principalmente para os pinos cônicos.

Para se conseguir o máximo de retenção do pino e uma maior proteção para a raiz, Trabert \& Cooney (1984) acreditavam que o comprimento desse pino deveria ser o maior possível, deixando $5 \mathrm{~mm}$ de remanescente de guta-percha, para não perder o selamento apical. Uma outra preocupação dos autores seria com a largura do pino, que não deveria ultrapassar um terço da menor largura da raiz.

Sorensen (1988) afirmou que nenhuma restauração ou material servem para todas as situações. A posição do dente no arco, a quantidade de estrutura remanescente, o tipo de retentor intra-radicular e o material devem ser considerados, em um bom diagnóstico. Para o autor, uma excessiva remoção das estruturas dentárias para facilitar a preparação do conduto deve ser evitada, preservando o remanescente dental, que proporcionará uma maior resistência àfratura.

As propriedades biomecânicas desejáveis para os retentores intraradiculares foram descritas por Standlee \& Caputo (1988). Para os autores, existem duas razões principais para o uso destes retentores: a primeira é dar retenção para a restauração final, principalmente quando há pouco 
remanescente coronário; e a segunda é proteger o remanescente dental, pela distribuição das forças oclusais, minimizando a intensidade das tensões na raiz.

As filosofias do diâmetro para preparo da raiz, que receberá um pino, foram revistas por Lloyd \& Palik (1993). Um segmento de pesquisadores, os conservadores, preconizava que o diâmetro do preparo deveria ser o mais delgado possível. O segundo segmento, o das proporções, recomendava que o espaço para o pino, na região apical, deveria ser igual a um terço do remanescente radicular. O terceiro, os preservadores, acreditava que deveria existir pelo menos $1 \mathrm{~mm}$ de remanescente radicular ao redor do espaço que receberá o pino.

De acordo com Manning et al,. (1995), a falta de fluidos dentinários, provocada pela perda da vitalidade do dente, provocava uma diminuição em suas propriedades físicas, tais como: módulo de elasticidade, resistência flexural e resistência compressiva. Esta diminuição em suas propriedades mecânicas poderia ser explicada pelo enfraquecimento das uniões intermoleculares do colágeno que forma a matriz orgânica da dentina, que contribui significativamente com as suas características físicas. Um outro motivo seria a própria técnica endodôntica que cria mudanças na estrutura tanto da coroa como do canal dentário, tornando-o mais susceptível às cargas mastigatórias.

Para Hunt \& Gogarnoiu (1996), a confecção de um retentor intraradicular deve seguir alguns princípios: promover um adequado selamento na interface entre o material do retentor e a superfície da raiz; deve existir 
uma adequada retenção; não deve provocar concentração de tensões na estrutura remanescente durante a preparação, inserção e função; e deve possuir rigidez necessária, não permitindo a fratura da raiz ou do próprio retentor. O retentor intra-radicular deve possuir alguns requisitos básicos, como: um adequado comprimento e assentamento nas paredes do canal. A parte coronária do retentor deve ser resistente o bastante para suportar as forças mastigatórias. A porção cervical coronária deve estar sustentada por estrutura dentária, tendo como resultado o efeito de cintamento.

Em uma revisão das técnicas existentes e das tendências atuais quanto àutilização de retentores intra-radiculares pré-fabricados e retentores intra-radiculares fundidos, Morgano (1996) concluiu que a colocação de pinos e núcleos debilitam a estrutura dentária e, sempre que possível, deveria ser realizado um tratamento restaurador, visando prevenir a perda de vitalidade do dente. Sempre que necessária, a colocação dos pinos deve seguir alguns princípios: o comprimento do pino não deve comprometer os 4 a $5 \mathrm{~mm}$ do vedamento apical do tratamento endodôntico; a largura não deve exceder a metade do diâmetro do tecido remanescente; deve haver de 1,5 a $2 \mathrm{~mm}$ de tecido remanescente dentário acima do limite cervical da coroa, para que haja um abraçamento em torno do pino, ou efeito de cintamento.

Para Deutsch et al. (1997), o comprimento do retentor intra-radicular é a chave do sucesso para a retenção tanto para retentores intra-radiculares fundidos, como para pinos pré-fabricados. No entanto, os autores recomendam que existem dois critérios que determinam o desenho do retentor intra-radicular: o primeiro é a manutenção de 3 a $5 \mathrm{~mm}$ de guta- 
percha na região apical para manter o selamento endodôntico e o segundo é que deve existir pelo menos $1 \mathrm{~mm}$ de espessura da raiz na região apical do pino.

No intuito de criar uma seqüência lógica para a seleção da técnica para restaurar dentes endodonticamente tratados, Smith \& Schuman (1997) recomendaram que, para os dentes anteriores, nem sempre estaria indicada a colocação de uma coroa total e que, dependendo da extensão da lesão, este poderia ser restaurado, utilizando um material adesivo. Já nos casos em que a extensão da lesão for muito grande e necessitar de uma restauração protética, estaria indicada a colocação de um retentor intraradicular.

Em uma longa revisão de literatura, Morgano \& Brackett (1999) estabeleceram princípios na restauração de dentes com tratamento endodôntico, que seriam com suportes de prótese fixa. Acreditaram que núcleo e pino fundidos são o tratamento de escolha para dentes com estrutura coronária moderada ou severamente destruída e que o comprimento do pino deve ser o maior possível, desde que a anatomia permita, deixando de 4 a $5 \mathrm{~mm}$ de guta-percha na região apical. Eles indicaram a preservação de no mínimo 1,5 a 2 mm de estrutura dental sobre o término marginal em torno de toda circunferência do pino (efeito cinta), obtendo assim as melhores propriedades mecânicas de retenção e melhorando a distribuição de tensões, transmitindo-as sobre o centro da raiz, evitando fraturas. 


\section{Resistência e tensões nos dentes tratados endodonticamente}

Preocupados com a distribuição de tensões sobre a raiz, em 1972, Hirschfeld \& Stern afirmaram que as cargas funcionais, que atuavam em dentes tratados endodonticamente, são transferidas, a partir da coroa, para a raiz e o tecido ósseo de suporte, através do núcleo e pino radicular. Recomendaram que o pino deveria apresentar, no mínimo, metade da altura óssea referente ao dente envolvido e que o pino fosse o mais longo possível sem prejudicar o selamento apical.

Standlee et al. (1972) pesquisaram a distribuição de tensões em três tipos de desenhos de retentores intra-radiculares (de paredes paralelas lisas, de paredes não paralelas ou cônicos e rosqueáveis de paredes paralelas) pelo método de fotoelasticidade. Os resultados mostraram que os pinos de paredes cônicas apresentaram a maior concentração de tensões quando comparados com os outros desenhos. Os autores concluíram que o comprimento do pino devia ser no mínimo igual ao comprimento da coroa clínica. Os pinos de paredes cônicas criaram tensões em forma de cunha, e os pinos de paredes paralelas e lisas apresentaram uma grande concentração de tensões na região apical.

Thresher \& Saito (1973) estudaram, por meio de elementos finitos, a distribuição de tensões no incisivo central superior, para determinar como o esforço era recebido e como a tensão era distribuída na estrutura óssea subjacente. O estudo foi realizado em modelo homogêneo e não homogêneo, isto é, no segundo modelo, com a representação das estruturas 
que compõem o dente e o suporte ósseo, tais como: esmalte, dentina e ligamento periodontal. Verificaram que os maiores deslocamentos ocorreram na metade superior do dente. O resultado provou a importância da utilização do modelo não homogêneo para determinar a distribuição das tensões.

Farah \& Craig (1974), utilizando o método dos elementos finitos, estudaram como três tipos diferentes de terminações de um preparo de coroa total em ouro poderiam influenciar na distribuição de tensões frente à aplicação de uma carga oclusal. Os tipos de terminações estudadas foram chanfro, degrau e degrau com bisel. Para esse estudo foi criado um modelo tridimensional axi-simétrico de um primeiro molar. Os autores observaram que a terminação do tipo chanfro demonstrou uma distribuição de tensões mais uniforme, seguida pelo degrau com bisel. O degrau foi o término que apresentou o pior resultado. Nos três tipos de terminação, foi observada uma grande concentração de tensões na região de interface entre a restauração de ouro e a dentina, o que poderia ocasionar uma falha no cimento.

Yetram et al. (1976) estudaram, mediante o método dos elementos finitos, a distribuição de tensões de um segundo pré-molar inferior hígido. Compararam este com um segundo pré-molar restaurado com uma coroa total de ouro, aplicando diferentes tipos de cargas. Os resultados demonstraram que, a aplicação de uma carga única na cúspide vestibular gerava uma tendência de rotação da coroa, produzindo uma grande concentração de forças de compressão na região do término do preparo da face vestibular e uma alta concentração de forças de tração na face oposta. 
Utilizando o método da fotoelasticidade, Henry (1977) analisou a distribuição de tensões ao redor de vários sistemas de pinos, concluindo que o desenho paralelo do pino distribui melhor as cargas, quando comparado ao desenho cônico. Desaconselhou o uso de pinos rosqueáveis e aconselhou preservar, ao máximo, a dentina coronária, pois conseguiria uma melhor distribuição de tensões sobre a raiz.

Utilizando um teste de resistência à fratura, Kantor \& Pines (1977) sugeriram que, para um dente despolpado com dentina coronária intacta após tratamento endodôntico conservador, é indicado o reforço com pino metálico, já que este praticamente dobra a resistência do dente. Em dentes com pouco remanescente dentinário na coroa, recomendaram a utilização da liga de ouro para a confecção do retentor intra-radicular fundido em dentes com tratamentos protéticos bem complicados e pinos pré-fabricados com núcleo de preechimento em resina composta, apenas para restaurações unitárias.

Johnson \& Sakumura (1978) encontraram retenção 4,5 vezes maior para pinos cilíndricos que para os cônicos. Entenderam que um aumento de 2 a $4 \mathrm{~mm}$ no comprimento resultava em aumento de $24 \%$ a $30 \%$ na capacidade retentiva.

Trabert et al. (1978) estudaram a resistência ao impacto, em incisivos centrais superiores, divididos em três grupos: dentes hígidos, dentes tratados endodonticamente e dentes restaurados com pinos pré- fabricados de aço inoxidável. Os valores de energia absorvida encontrados para cada grupo foram comparados com as mudanças no tamanho do conduto e no 
diâmetro do pino. Os resultados demonstraram que a preservação das estruturas internas do dente e o uso de pinos de pequeno diâmetro, proporcionaram o máximo de resistência àfratura.

Em 1979, Guzy \& Nicholls, em um teste de fratura, onde foram utilizados 59 dentes incisivos e caninos extraídos, isentos de cáries, trincas ou fraturas, posteriormente tratados endodonticamente, dos quais trinta foram reforçados com pinos do sistema Endo-Post ${ }^{*}$, observaram que, em 53 dos 59 dentes, as fraturas ocorreram abaixo do limite amelo-cementário. Não houve diferença estatisticamente significante entre dentes com e sem pino de reforço.

Davy et al. (1981), em um estudo teórico, utilizaram o método dos elementos finitos em modelos bidimensionais para comparar as tensões sobre um incisivo central superior hígido e restaurado por uma coroa cerâmica e um retentor intra-radicular. Foi avaliada comparativamente uma série de desenhos para os pinos endodônticos. Quando comparado o modelo do dente hígido com o dente restaurado, a maior concentração de tensões na dentina foi encontrada no dente hígido, o que pode ser explicado pela presença do pino no dente restaurado, que, devido ao seu maior módulo de elasticidade, reduz o nível de tensões na dentina subjacente. Os resultados mostraram pequenas alterações no padrão de tensões pela variação do diâmetro, comprimento e forma do pino. Pinos cilíndricos com maiores diâmetros foram os que obtiveram os melhores resultados.

* Whaledent International Co. New York, NY 
O efeito da perda em altura do osso alveolar, relacionado com a magnitude e a distribuição de tensão na dentina, foi verificado por Reinhardt et al. (1983), com o auxílio do método dos elementos finitos. Foram utilizados incisivos centrais superiores, tratados endodonticamente e restaurados com pinos intra-radiculares em quatro níveis de suporte periodontal. Os autores concluíram que as tensões na dentina aumentavam proporcionalmente com a migração do nível ósseo. Esse aumento foi significativo quando o nível de perda óssea atingiu $4 \mathrm{~mm}$.

Com o objetivo de comparar os resultados de um modelo tridimensional com um modelo bidimensional, utilizado em um estudo anterior, Rubin et al, (1983) analisaram a distribuição de tensões em um primeiro molar hígido, pelo método dos elementos finitos em modelos tridimensionais. Os autores concluíram que a criação do modelo tridimensional oferece melhorias frente aos modelos bidimensionais, principalmente por permitir uma reprodução anatômica e forças de carregamento mais complexas, reproduzindo uma situação mais próxima do real.

Vree et al. (1983) compararam os resultados da distribuição das tensões nas estruturas dos dentes pela análise fotoelástica bidimensional e pelo método dos elementos finitos com modelos bidimensionais e tridimensionais axi-simétricos. Os autores concluíram que o método dos elementos finitos apresenta inúmeras vantagens sobre o método fotoelástico. Sugerem que um modelo bidimensional não é tão fiel quanto um 
modelo tridimensional axi-simétrico na análise das tensões, pois este se aproxima muito da estrutura do dente.

Em um estudo clínico, Sorensen \& Martinoff (1984) avaliaram, em 1273 pacientes, a longevidade de dentes restaurados após tratamento endodôntico. Concluíram que não houve um aumento significante na resistência à fratura com reforço intra-radicular. Para os dentes anteriores, houve uma média de sucesso de $84,7 \%$ para os dentes restaurados sem reforço intra-radicular e $89,4 \%$ com a colocação de um pino, o que faz os autores acreditarem que a remoção de estrutura dental, durante o preparo do pino, deve ser evitada.

Trope et al. (1985) testaram a resistência à fratura de incisivos centrais superiores hígidos e tratados endodonticamente, restaurando o espaço do preparo do canal com 8 métodos diferentes. As forças de compressão foram aplicadas com uma inclinação de $50^{\circ}$ em relação ao longo eixo do dente, na região de cíngulo, até que ocorresse a fratura. Os autores concluíram que os dentes preparados para receberem retentores intra-radiculares eram enfraquecidos substancialmente; a colocação de um pino não aumentou consideravelmente a resistência à fratura e quando o espaço preparado foi preenchido com resina composta, o dente foi fortalecido.

Utilizando o método dos elementos finitos, Pao et al., (1987) analisaram a distribuição de tensões em um incisivo central superior, tratado endodonticamente e restaurado com pinos metálicos de terminação apical cônica, associado a vários graus de envolvimento periodontal. Os autores 
concluíram que os pinos, com terminação cônica, oferecem vantagens sobre aqueles com terminação cilíndrica. Quando o suporte periodontal apresentou-se diminuído, a inserção de pinos com a terminação cônica reduziu a tensão na dentina, como também a possibilidade de perfuração da raiz, além de preservar uma maior quantidade de dentina na região periapical.

Hunter et al. (1989) avaliaram o preparo do conduto e a colocação do retentor intra-radicular em incisivos centrais superiores, através do método de fotoelasticidade. Foram aplicadas cargas de 210,5 N com uma inclinação de $130^{\circ}$ em relação ao longo eixo do dente. Os autores concluíram que a remoção de estrutura dental, durante o preparo para receber um retentor intra-radicular, é acompanhado de um aumento proporcional de tensões na região cervical do dente; um pequeno alargamento do canal resultou em um aumento moderado do diâmetro do pino, que não enfraqueceu substancialmente a raiz; se o canal for bastante alargado, um pino com comprimento adequado e diâmetro moderado aumentou sua resistência substancialmente, evidenciando que o comprimento do pino é mais importante do que o diâmetro na redução das tensões cervicais, devendo-se evitar o uso do pino curto e largo.

Assif et al. (1989), utilizando a análise fotoelástica, demonstraram que, quando uma força é aplicada na coroa com $30^{\circ}$ de inclinação em relação ao seu longo eixo, as tensões são transmitidas æ̀̀ margens da coroa, criando um fulcro na região da crista óssea alveolar, quando o dente está na cavidade bucal. A presença do retentor intra-radicular não diminui a 
concentração de tensões na região cervical da coroa, pois as tensões estariam sendo absorvidas pelo material mais rígido (coroa), para posteriormente serem transmitidas ao material menos rígido (raiz).

Sorensen \& Engelman (1990) estudaram o tipo do retentor intraradicular (cônicos e cinlíndricos), utilizando o cimento de fosfato de zinco. A carga aplicada teve uma angulação de $130^{\circ}$ em relação ao longo eixo do dente. Os resultados demonstraram que os pinos cilíndricos apresentavam a menor freqüência de fraturas, e os pinos cônicos apresentavam fraturas mais envolventes, seguindo em direção apical.

Cailleteau et al. (1992) estudaram a distribuição de tensões pelo método dos elementos finitos em modelo bidimensional de um incisivo central superior tratado endodonticamente, restaurado de diferentes maneiras e comparado com um dente hígido, aplicando-se uma carga perpendicular à superfície lingual da coroa. Os resultados demonstraram que a colocação de um retentor intra-radicular altera o padrão de distribuição de forças ao longo da raiz, quando comparado à um dente hígido. E concluíram que a colocação de um retentor intra-radicular não estaria recomendada em todos os casos em que um dente tratado endodonticamente for restaurado, especialmente nos dentes que possuam estrutura suficiente para receber uma simples restauração.

O efeito da colocação dos retentores intra-radiculares na redução das tensões na dentina foi estudado por Ko et al., (1992), utilizando o método dos elementos finitos em um modelo tridimensional de um incisivo central superior. Concluíram que, sob cargas horizontais, os pinos reduziam as 
tensões de 3 a $8 \%$. Sob carga vertical, as tensões na dentina foram reduzidas em torno de $20 \%$. Como incisivos e caninos não estão sujeitos a cargas puramente verticais, o efeito de reforço dos pinos não foi considerado.

Mitchell \& Kennedy (1992) realizaram um estudo semi-empírico, para determinar entre os vários componentes que promovem a retenção dos retentores intra-radiculares, qual deles falharia quando fosse aplicada uma carga com inclinação de $50^{\circ}$ na superfície palatina de dentes incisivos centrais superiores. Os resultados demonstraram que, quando a força era aplicada, aparecia um defeito entre a coroa e a superfície da raiz, na face palatina do dente, enquanto a região vestibular permanecia intacta, indicando que, quando o dente recebe cargas oblíquas, estaria sendo gerado um fulcro na face vestibular, na interface dente/coroa.

Millot \& Stein (1992) utilizaram um análogo de um incisivo central superior tratado endodonticamente, feito em resina, para investigar a resistência à fratura, quando utilizados três diferentes desenhos de retentores intra-radiculares: pino e núcleo fundidos, pino Para-Post Plus e pino Flexi-Post. * A construção do núcleo de preenchimento foi feita com Ketac Silver**, e para cada análogo foi feita uma coroa metálica. Dois tipos de linha de terminação foram confeccionados: chanfro largo e chanfro largo com bisel de $1 \mathrm{~mm}$ em torno de todo o preparo. Foram aplicadas forças na superfície lingual da coroa, com uma inclinação de $120^{\circ}$, até que as fraturas ocorressem. Os autores chegaram æ̀s seguintes conclusões: a) quando o

* Essential Dental Systems, New York, N.Y.

** Espe, Seenfeld/ Oberbay, Germany 
máximo de estrutura é preservada, a seleção do pino tem pouco efeito na resistência à fratura da raiz; b) a forma de preparo com uma linha de terminação biselada oferece um aumento na resistência à fratura e c) uma linha de terminação sem bisel favorece a incidência de fraturas verticais.

Em um acompanhamento clínico de 3 anos, Hatzikyriakos et al., (1992) avaliaram, em 150 pacientes, 154 retentores intra-radiculares. Dois tipos eram de pinos pré-fabricados e núcleo de preenchimento em resina foto-polimerizável, e um terceiro tipo com pino e núcleo fundidos em metal. O retentor intra-radicular fundido apresentou uma pequena vantagem no período avaliado.

Um estudo da distribuição das tensões em um dente natural e em um dente restaurado com coroa metalo-cerâmica e retentor intra-radicular fundido, foi realizado por Mori (1994) com o auxílio do método dos elementos finitos em um modelo bidimensional de um $2^{\circ}$ pré-molar inferior, sob carga axial. Os resultados indicaram um acúmulo de tensões de von Mises, na metade vestibular da raiz do dente natural e do dente restaurado. As maiores tensões se concentraram no ponto de aplicação das cargas, sendo maiores no dente restaurado, em função do maior módulo de elasticidade dos materiais restauradores.

No estudo realizado por Ho et al., (1994), foi criado um modelo matemático tridimensional de um incisivo central. superior, tratado endodonticamente e restaurado com retentor intra-radicular, para analisar as tensões, quando aplicada uma carga funcional e comparar com um dente hígido. Os autores concluíram que a colocação de um retentor intra- 
radicular não traria vantagem no que diz respeito a reforço da estrutura remanescente, quando a estrutura coronária for preservada e o preparo do canal for o mais conservador possível.

O comportamento mecânico das estruturas de um dente tratado endodonticamente foi estudado por Pierrisnard et al., (1994a), utilizando o método dos elementos finitos em modelo tridimensional de um pré-molar uniradicular, restaurado com uma coroa de $\mathrm{Ni}-\mathrm{Cr}$, sob uma carga axial de $15 \mathrm{~N}$, variando, elementos como: o comprimento e diâmetro do pino e a influência do suporte periodontal. Os autores concluíram que o comprimento do pino foi o fator mais significativo; pinos longos geraram menores tensões que pinos curtos. Observaram também que, quando o suporte ósseo está reduzido, a concentração de tensões aumenta.

Em um estudo posterior, Pierrisnard et al. (1994b) empregaram a mesma metodologia para analisar a distribuição de tensões nas estruturas dentais, em duas situações distintas: pino radicular com núcleo de preenchimento e pino radicular e núcleo fundidos. Concluíram que o pino e núcleo fundidos distribuem melhor a carga aplicada, especialmente ao redor da área crítica localizada a 2 mm da junção amelo-cementária.

Utilizando o mesmo modelo usado anteriormente, Pierrisnard et al., (1995) empregaram a mesma metodologia para avaliar a distribuição de tensões em função do tipo de material constituinte do pino: níquel-cromo, titânio ou ouro. Os resultados mostraram que as concentrações de tensões na dentina ao redor do pino são inversamente proporcionais ao módulo de 
elasticidade do material utilizado, significando que, quanto mais rígido for o material do pino, menor será a carga transmitida àdentina adjacente.

Cohen et al., (1996) compararam a resistência à fratura em quatro materiais diferentes, usados em núcleos de preenchimento e cinco diferentes pinos pré-fabricados. Os autores encontraram a maioria das falhas (79\%) nos núcleos de preenchimento, e $21 \%$ das falhas restantes ocorreu por fratura da raiz, indicando que o ponto crítico quando se usa pino pré-fabricado mais núcleo de preenchimento, é um micro-movimento do núcleo de preenchimento que pode gerar uma falha na adaptação da coroa e conseqüente infiltração marginal.

Holmes et al., (1996) realizaram um estudo para avaliar o efeito das dimensões do retentor intra-radicular na distribuição de tensões de um dente tratado endodonticamente e restaurado com coroa total. Foi criado um modelo matemático axi-simétrico de um canino inferior e aplicada uma carga na face vestibular com uma inclinação de $45^{\circ}$. Os autores concluíram que, quanto mais curto o comprimento do pino intra-radicular, maior a formação de tensões, tanto de compressão como de tração, nas paredes da raiz e que a maior concentração de forças de tração encontrava-se na parede vestibular do canal e as maiores forças de compressão estavam localizadas na parede palatina, ambas no terço coronário da raiz.

Veiga (1996) fez um estudo comparativo, pelo método dos elementos finitos, da distribuição das tensões internas, pelo critério de von Mises, em modelos bidimensionais de dente hígido e dentes tratados endodonticamente, restaurados com retentores intra-radiculares fundidos, longo e curto, sob 
carga axial e horizontal para vestibular. $\mathrm{O}$ autor concluiu que as maiores tensões foram observadas na estrutura óssea de suporte, em ambas as cargas, e que o padrão de distribuição de tensões, no modelo de dentes restaurados com retentor intra-radicular fundido longo, foi similar ao do dente hígido. O dente restaurado com retentor intra-radicular fundido curto apresentou maiores valores e maior área de tensão acumulada.

Em 1997, Lambjerg-Hansen \& Amussen avaliaram 22 pinos préfabricados com relação à rigidez, ao limite elástico e à resistência à fratura. Os autores concluíram que as variações encontradas nos valores de rigidez, resistência à fratura e limite de elasticidade em pinos de mesmo diâmetro e material podem ser explicadas pelo tipo de desenho dos pinos, que erradamente priorizam a retenção e não a estabilidade. Eles advogaram a utilização de pinos endodônticos com a porção coronal cilíndrica e porção apical cônica.

Utilizando o método dos elementos finitos em modelos bidimensionais, Vasconcellos (1998) analisou o comportamento de duas próteses fixas de três elementos, suportadas por um pré-molar e um molar inferior com os canais tratados endodonticamente, comparando um modelo com retentores intra-radiculares fundidos e outro com retentores intraradiculares pré-fabricados mais núcleos de preenchimento em resina composta. Os resultados mostraram que, devido ao movimento de deflexão da prótese parcial fixa, tensões se concentram na região disto-cervical do pré-molar, sendo maiores nos modelos com pinos pré-fabricados e núcleo de preenchimento, e que, neste modelo, concentram-se maiores tensões 
sobre os retentores intra-radiculares, provavelmente pelo menor módulo de elasticidade da resina composta quando comparada com o ouro do núcleo fundido.

Martines-Insua et al. (1998) compararam a resistência à fratura de dentes restaurados com pino e núcleo fundidos e dentes restaurados com pinos pré-fabricados de fibras de carbono e núcleo de preenchimento em resina composta. O tamanho e forma dos pinos foram idênticos nos dois grupos e ambos receberam uma coroa de níquel-cromo como restauração final. A resistência à fratura foi significantemente maior no grupo de pino e núcleo fundidos. Os dentes restaurados com pinos pré-fabricados e núcleos de preenchimento mostraram falhas na interface pino/núcleo de preenchimento antes da fratura do dente.

Saldivar Bocangel (1999), utilizando o método dos elementos finitos, comparou a distribuição de tensões em um incisivo central superior hígido e em um incisivo central superior tratado endodonticamente e reconstruído com coroa oca de porcelana com o uso de diferentes materiais nos retentores intra-radiculares. Foi aplicada uma carga de $100 \mathrm{~N}$ na superfície lingual dos dentes. Baseado nos resultados obtidos, o autor concluiu que a colocação de um retentor intra-radicular em um dente endodonticamente tratado altera o padrão de tensões geradas e que este pode ser também alterado, dependendo do material do retentor intra-radicular utilizado.

Com o propósito de avaliar a influência do comprimento do pino e do efeito cinta, Isidor et al. (1999) compararam a resistência à fratura em dentes bovinos com retenção intra-radicular obtidas com pinos pré- 
fabricados Para-Post e núcleo de preenchimento em resina composta e pino e núcleo fundidos. Os dentes foram restaurados com coroas de ouro. Foram aplicadas cargas cíclicas com inclinação de $45^{\circ}$ sobre a face palatina da coroa. O comprimento do pino variou de 5,0, 7,5 e $10 \mathrm{~mm}$, e o comprimento da cinta coronária foi de 0, 1,5 e 2,5 mm. Os resultados mostraram que o comprimento da cinta coronária foi mais importante que o do pino na análise de resistência à fratura, entretanto, os melhores resultados foram encontrados entre os pinos com $10 \mathrm{~mm}$ de comprimento e 2,5 mm de cinta.

Borget \& Boston em 2000 descreveram um caso clínico em que, após a perda da prótese fixa e do núcleo de preenchimento por recidiva de cárie, foi aproveitado o pino pré-fabricado intra-radicular, que não pôde ser removido, para dar retenção ao novo núcleo. Segundo os autores, núcleos de preenchimento em resina podem falhar, por se flexionarem durante a função. Recomendaram a utilização de um núcleo metálico fundido, que seria colado a estrutura dentária remanescente para reduzir o fenômeno da de flexão do núcleo. 


\section{PROPOSIÇÃO}

A revisão da literatura mostra a preocupação dos autores com o desenho dos retentores intra-radiculares e como o formato do pino modifica a distribuição de tensões sobre o remanescente dental. Neste trabalho, procurou-se estudar:

1. A comparação do retentor intra-radicular pré-fabricado de formato cilíndrico/ escalonado com um retentor intra-radicular fundido de formato cônico.

2. A maneira como ocorre a distribuição de tensões na dentina radicular quando da utilização do retentor intra-radicular pré-fabricado de formato cilíndrico/escalonado e o fundido de formato cônico.

3. O que ocorre com a película de cimento de fosfato de zinco, responsável pela cimentação da coroa e dos retentores intra-radiculares, quanto æ̀̀ tensões de von Mises. 


\section{MATERIAL E MÉTODOS}

A aplicação da Física em Biologia e Odontologia não é recente e tem desempenhado um papel essencial em avanços nessas áreas. Uma alternativa cada vez mais viável, dados os avanços no campo da informática, está centrada nos métodos numéricos de computação que, aplicados ao problema em questão e valendo-se do equacionamento teórico similar, produzem resultados muito próximos do real, sendo de grande confiabilidade.

O método dos elementos finitos é uma técnica pela qual pode ser recriado matematicamente o comportamento de um sistema físico determinado, em outras palavras, o protótipo físico pode ser estudado mediante a criação de um modelo matemático preciso. Este método faz uso de um computador para resolver um grande número de equações matemáticas, as quais simulam as propriedades físicas da estrutura a ser analisada.

O método possui duas características especiais: os elementos finitos e as funções de interpolação. Os elementos finitos são subdivisões do modelo, pequenas o suficiente para tornar viáveis as abordagens analíticas em cada um desses elementos e na combinação dos seus efeitos. Esses 
elementos são montados, formando uma estrutura de forma determinada. Os elementos são interconectados por seus pontos nodais ou nós, que são os pontos de união entre os elementos. As funções de interpolação permitem, uma vez determinados os deslocamentos em cada nó, interpolar deslocamentos e calcular deformações e tensões em qualquer ponto da estrutura.

As informações essenciais requeridas para o estudo de uma estrutura através do método dos elementos finitos são: criação da geometria da estrutura, fixação do modelo, aplicação das cargas e as propriedades dos materiais a serem estudados.

As propriedades dos materiais necessárias para que o programa possa resolver o sistema de equações são (Beer \& Johnston,1999):

Módulo de elasticidade "E": o módulo de elasticidade é definido como a relação existente entre o esforço específico e a elongação específica (unitária). Este valor geralmente é obtido mediante um ensaio físico de tração ou compressão. O módulo de elasticidade é basicamente o grau de elasticidade de um material. Isso quer dizer que, quando o módulo de elasticidade de um material for grande para uma força aplicada, a deformação linear do material será pequena.

Coeficiente de Poisson "v": o coeficiente de Poisson é definido, basicamente, como a relação que existe, quando aplicada uma carga num corpo, entre o sentido da aplicação da carga e a deformação do corpo no sentido contrário. Isso quer dizer que, quando se produz uma força ao longo 
do eixo $X$ de um material, produz-se também uma deformação nos eixos $Y$ e Z .

método dos elementos finitos, para um dado caso de estrutura real, pode ser resumido nos seguintes passos.

- Modelagem geométrica: cria-se um modelo matemático (geométrico) do objeto em estudo. Tipicamente, isto é realizado em um programa de computador capaz de produzir um modelo matemático da estrutura mecânica em consideração.

- Modelagem por elementos finitos: subdivide-se o modelo geométrico em elementos, interconectados por seus pontos nodais ou nós, os quais se encontram no sistema de coordenadas $X, Y, Z$. O conjunto resultante é chamado de malha. Para a criação dessa malha, as propriedades dos materiais, que esta representa, têm que ser designados.

- Definição do ambiente: durante esta fase, são conferidos ao modelo matemático as condições de fixação e carregamento, que simularão o modelo físico real.

- Análise: calculam-se os resultados (deslocamentos, tensões e deformações), ou seja, as respostas do modelo æ̀s solicitações de maneira estática, dinâmica ou térmica.

- Verificação dos resultados: apresentação dos resultados em forma gráfica ou tabelas.

Pode-se sintetizar a análise por elementos finitos em três passos: préprocessamento, processamento propriamente dito e pós-processamento. 
No pré-processamento, modela-se a estrutura a ser analisada, informando-se características físicas dos materiais envolvidos. As estruturas são divididas através de elementos e nós para que, posteriormente, sejam aplicadas as condições de fixação e carregamento.

No módulo de processamento propriamente dito, há o desenvolvimento do algorítimo para uma solução de máxima precisão, velocidade e confiança.

Finalmente, no pós-processamento tem-se uma perfeita visualização dos resultados, apresentando ferramentas para procurar mostrar e conseguir novos cálculos através dos resultados obtidos na análise.

\subsection{Descrição dos modelos}

A proposta do trabalho foi analisar a distribuição de tensões em um canino superior, tratado endodonticamente e restaurado por uma coroa metalo-cerâmica com a retenção obtida por dois diferentes formatos de retentores intra-radiculares.

$\mathrm{Na}$ tentativa de saber como um novo formato de retentor intraradicular transmitiria as forças aplicadas ao cimento fosfato de zinco e tecidos adjacentes, foram criados dois modelos a partir de uma imagem de um canino superior. Em ambos, a porção coronária foi removida e restaurada por uma coroa metalo-cerâmica e foram submetidos às mesmas condições de carregamento. 


\section{Modelagem geométrica}

Com o objetivo de se confeccionar um modelo matemático fiel æ̀s dimensões e características anatômicas normalmente encontradas, foi criada uma peça anatômica de estudo, seccionando um canino superior, com comprimento de $26,4 \mathrm{~mm}$, estando na média encontrada por Della Serra \& Ferreira, 1981 , que foi $26,5 \mathrm{~mm}$, com um corte axio-vestíbulo-lingual, utilizando um disco diamantado dupla face (Meisinger, Germany). As superfícies foram regularizadas numa máquina de recortar e polir (PolitrizEcomet 3 e 4). Neste momento, a peça foi copiada por um "scanner" de mesa, Colorpage-HR5 (genius), passando a imagem para o programa Corel Draw 8.0, (Corel corp, USA) onde o desenho geométrico foi obtido. Dessa forma, evitou-se a possibilidade de falhas na proporcionalidade da ampliação, não necessitando de recursos adicionais para capturar a imagem (Vasconcellos, 1998). Utilizando-se ferramenta oferecida pelo Corel Draw 8.0, obteve-se a ampliação da imagem que facilitou a delimitação das estruturas da peça.

$\mathrm{Na}$ primeira situação, o desenho representou uma prótese unitária metalo-cerâmica, sobre o remanescente radicular da imagem digitalizada do canino superior, tratado endodonticamente e com retentor intra-radicular pré-fabricado escalonado fundido (pino e núcleo) numa peça única, com 18 $\mathrm{mm}$ de comprimento, conforme o desenho cedido pelo fabricante do Optipost Wurzeistift ${ }^{*}$ o qual é indicado para caninos. Neste momento, foi realizada

* GeBR. Brassler, Mengo, Alemanha. 
uma pequena modificação no comprimento do canino superior, para que fosse mantida as proporções ideais na confecção de um retentor intraradicular (Abdulla et al., 1974; Deutsch et al., 1997), com o objetivo de simular uma situação clínica, onde o formato do retentor intra-radicular pudesse ser estudado sem nenhuma condição anatômica desfavorável, Isso resultou em um canino com $24,5 \mathrm{~mm}$ de comprimento e $7,5 \mathrm{~mm}$ de largura, na região cervical.

A coroa metalo-cerâmica teve o contorno e a espessura média do esmalte na parte correspondente à cerâmica e um término em forma de ombro com bisel de $1 \mathrm{~mm}$ em torno do dente, pois, segundo Millot \& Stein (1992), a linha de terminação biselada oferece um aumento na resistência à fratura. A infra-estrutura metálica, com uma espessura média de $0,3 \mathrm{~mm}$, foi recoberta por uma camada de cerâmica que pode variar de 0,7 a 1,7 mm de espessura (Yamomoto, 1985). A espessura do cimento fosfato de zinco, usado tanto para cimentação da coroa e do retentor intra-radicular, apresentou uma espessura média de 30 a $100 \mu$, dependendo do angulo da localização da linha de cimentação (Shillingburg et al. 1988). A porção radicular do retentor foi colocada no interior da raiz, deixando $4 \mathrm{~mm}$ de gutapercha, para não prejudicar o selamento apical do tratamento endodôntico. (Colman, 1979 ; Deutsh et al. 1997).

O elemento dentário foi inserido em um bloco de tecido de suporte que contém as seguintes estruturas anatômicas, com as seguintes dimensões : 
Uma camada de osso cortical com $2 \mathrm{~mm}$ de espessura envolve todo o bloco do tecido de suporte ( Holmes et al. 1996).

Uma camada uniforme de ligamento periodontal com 0,175 mm envolve toda a raiz (Grant et al. 1972 ).

Uma camada de osso cortical com $0,5 \mathrm{~mm}$ de espessura envolve 0 ligamento periodontal (Grant et al. 1972).

Uma camada de osso esponjoso preenche a porção entre o ligamento periodontal e a porção de osso cortical, que envolve o bloco de tecido de suporte (Holmes et al. 1996).

O desenho foi hemi-secionado, aproveitando-se a porção vestibular do modelo. Nesta fase o desenho foi salvo em formato DXF, em que cada ponto possui uma cordenada $\mathrm{X}, \mathrm{Y}$ (fig.1), sendo possível, assim, ser importado para o programa MSC Nastran for Windows (versão 4.5). Nesta fase foram conferidas todas as particularidades do modelo, tais como, espessura do cimento e do ligamento periodontal, para que cada elemento que compõe o desenho remanescente possa ser girado $360^{\circ}$ em torno do seu eixo central, criando uma estrutura geométrica axi-simétrica, que, segundo Holmes et al. (1996), permite, a partir de um modelo bidimensional, construir uma estrutura tridimensional, onde as tensões serão estudadas em um modelo tridimensional axi-simétrico, obtendo respostas mais precisas e bem próximas de uma estrutura real. 


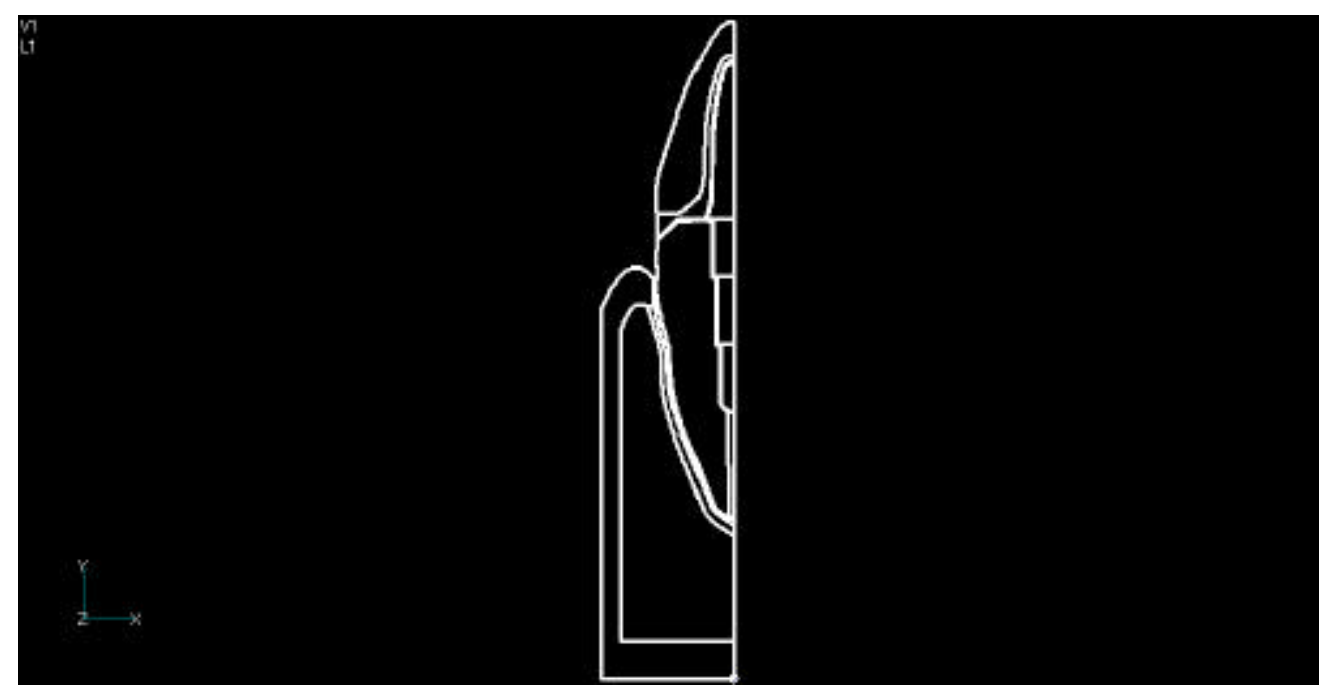

Figura1 - Modelo hemi-seccionado com retentor intra-radicular pré-fabricado escalonado, com pino e núcleo fundidos numa peça única, e linha de terminação do preparo dental em ombro com bisel de $1 \mathrm{~mm}$.

O segundo modelo representou o mesmo desenho anterior, com uma modificação no desenho do pino do retentor intra-radicular, que apresentou um pino com formato cônico. Este formato do pino foi realizado, unindo as extremidades dos degraus do pino escalonado, modificando o módulo de elasticidade e o coeficiente de Poisson destes espaços de dentina, transformando-os em titânio, para isso o pino teve seu volume aumentado de $38,5 \mathrm{~mm}^{3}$ para $44,5 \mathrm{~mm}^{3}$, um aumento de $13,50 \%$. Foi tomando o cuidado de não alterar o desenho do terço apical do pino, criando, assim, um pino de formato cônico, com 16º de conicidade, acompanhando a anatomia do canal radicular (Fig. 2). 


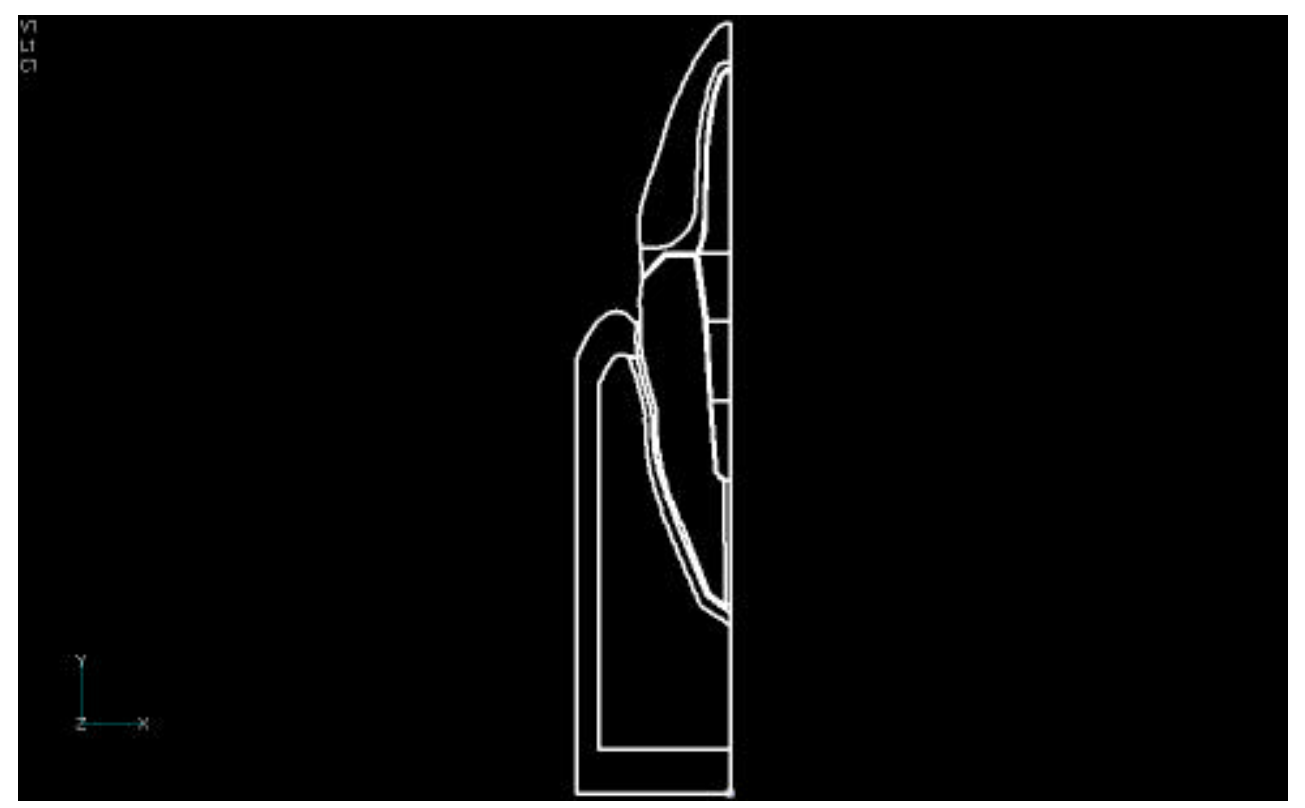

Fig. 2 - Modelo hemi-seccionado com retentor intra-radicular com formato cônico, e linha de terminação do preparo dental em ombro com bisel de 1 $\mathrm{mm}$.

Por se tratar de um modelo axi-simétrico de canino superior, convencionou-se chamar a região, onde as cargas foram aplicadas, de face palatina, e de face vestibular a região oposta. Também com o objetivo de facilitar a leitura, o modelo com retentor intra-radicular pré-fabricado escalonado passou a ser chamado de modelo 1 , e o modelo com retentor intra-radicular fundido de formato cônico, de modelo 2.

\section{Modelagem por elementos finitos}

Nesta fase, o modelo geométrico foi dividido em um número determinado de elementos, interconectados por seus nós. 
Antes de serem criados os elementos e nós, devem ser definidas as propriedades dos materiais utilizados. O cemento e a dentina foram considerados como um mesmo material, devido à semelhança de suas propriedades físicas. Estas foram obtidas na literatura já existente, conforme Tabela 4.1.

Tabela 4.1 - Propriedades físicas em Mega Pascal dos materiais usados na pesquisa:

PROPRIEDADES

\begin{tabular}{|c|c|c|c|}
\hline Materiais & $\begin{array}{c}\text { Módulo de elasticidade } \\
\text { em Mpa }\end{array}$ & $\begin{array}{c}\text { Coeficiente de } \\
\text { Poisson "v" }\end{array}$ & Referência \\
\hline Porcelana & 70.000 & 0.19 & $\begin{array}{c}\text { Seghi et } \\
\text { al(1992) }\end{array}$ \\
\hline $\begin{array}{c}\text { Ouro } \\
\text { cerâmico }\end{array}$ & 103.000 & 0.33 & $\begin{array}{c}\text { Morris } \\
(1989)\end{array}$ \\
\hline Dentina & 14.700 & 0.31 & $\begin{array}{c}\text { Sano et al. } \\
\text { (1994) }\end{array}$ \\
\hline $\begin{array}{c}\text { Titânio } \\
\text { Fosfato de } \\
\text { zinco }\end{array}$ & 117.000 & 0.33 & $\begin{array}{c}\text { O'Brien } \\
(1997)\end{array}$ \\
\hline $\begin{array}{c}\text { Guta } \\
\text { percha }\end{array}$ & 13.700 & 0.35 & $\begin{array}{c}\text { Powers } \\
\text { et.al.(1976) }\end{array}$ \\
\hline $\begin{array}{c}\text { Osso } \\
\text { cortical }\end{array}$ & 0.69 & 0.45 & $\begin{array}{c}\text { Friedman et } \\
\text { al. (1975) }\end{array}$ \\
\hline $\begin{array}{c}\text { Osso } \\
\text { esponjoso }\end{array}$ & 14.700 & 0,30 & $\begin{array}{c}\text { Moroi et al. } \\
\text { (1993) }\end{array}$ \\
\hline $\begin{array}{c}\text { Lig. } \\
\text { Periodonta } \\
\text { I }\end{array}$ & 490 & 0.30 & $\begin{array}{c}\text { Moroi et al. } \\
(1993)\end{array}$ \\
\hline
\end{tabular}

Após serem inseridas as propriedades dos materiais, a criação dos nós dos elementos é realizada automaticamente pelo programa, embora o tamanho, número e forma dos elementos possam ser especificados pelo 
operador. Nesta fase, o programa criou 17.967 nós e 35.820 elementos triangulares para o modelo com retentor intra-radicular escalonado e 17.797 nós e 35.480 elementos triangulares para o retentor intra-radicular de formato cônico.

\subsection{Definição do ambiente}

Nas duas situações, foi simulada a aplicação de uma carga estática de $100 \mathrm{~N}$, de acordo com Ho et al. (1994) e Holmes et al. (1996), dividida por 5 pontos, $2 \mathrm{~mm}$ abaixo da ponta de cúspide. Foram aplicadas cargas oblíquas, com uma inclinação de $45^{\circ}$, em relação ao longo eixo do dente, tentando simular as forças geradas durante o ciclo mastigatório.

Para que possa ser realizada a análise estática da força aplicada, é necessário que o modelo possua condições de fixação, que define como a união entre as estruturas se comportam quando da aplicação de uma força. Para isso, considerou-se fixa a região da base dos modelos.

Para o presente trabalho, foram criados dois modelos com geometria tridimensional axi-simétrica, para análise pelo método dos elementos finitos. O programa utilizado nas fases de pré-processamento, processamento propriamente dito e pós processamento foi o MSC-Nastran for Windows versão 4.5 de propriedade do departamento de dentística da FOUSP. 


\subsection{Análise das tensões}

A distribuição de tensões em um material é obtida indiretamente através da observação e da medida das deformações sofridas, quando sobre ele exercemos uma determinada força. Quando aplicamos uma determinada carga sobre um material, este resiste com uma reação elástica chamada tensão.

Utilizando o programa de elementos finitos, obtêm-se as tensões de tração, compressão e cisalhamento nos eixos independentes x, y e z para cada um dos elementos que compõe a malha tridimensional.

A capacidade operacional do programa permite analisar as tensões, tanto no modelo completo como nas estruturas que o compõem, isoladamente e em diversas posições de rotação ou translação. Permite também, através de cortes, a análise interna, em qualquer ponto da estrutura, após o carregamento.

Segundo Beer \& Jonston (1999), quando um elemento estiver sob ação de um estado uni-axial de tensões (fig. 3), o valor da tensão normal $\sigma_{x}$, responsável pelo escoamento do material, pode ser obtido a partir de um ensaio de tração, executado num corpo de prova de material idêntico, uma vez que o elemento ou o componente do corpo de prova está sob o mesmo tipo de solicitação, isto é, sob o mesmo estado de tensões. Assim, mesmo não se considerando os mecanismos reais que levam o material ao escoamento, pode-se afirmar que o elemento, logo o conjunto, estará seguro 
enquanto $\sigma_{\mathrm{x}}$ for menor que $\sigma_{\mathrm{e}}$, correspondendo à tensão de escoamento do material no teste de tração.

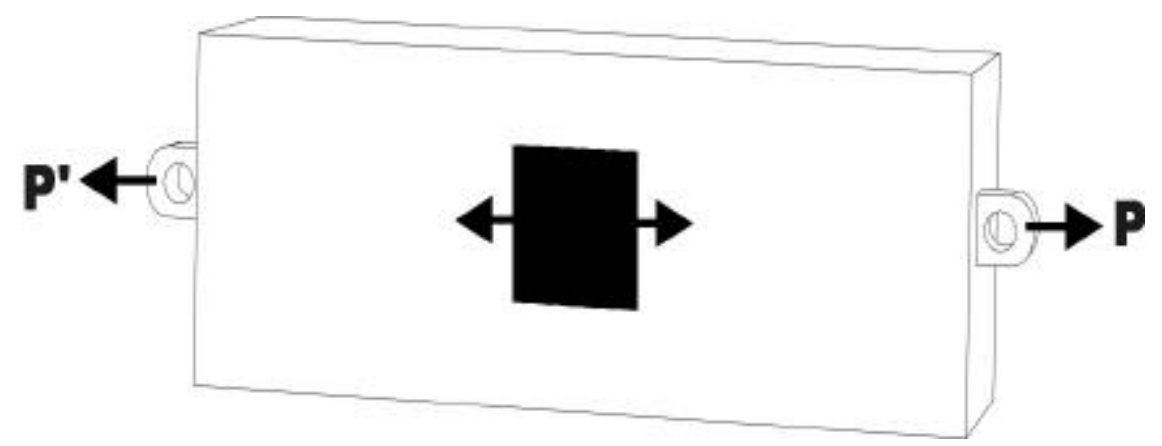

Figura 3 - Estado uni-axial das tensões

No caso em que o elemento estiver em um estado bi-axial de tensões, não será possível predizer, a partir de um ensaio de tração uni- axial, se o material que o compõe, romper-se-á ou não (fig. 4). Para tal predição, é necessário estabelecer previamente um critério que considere o mecanismo real de ruptura do material, permitindo a comparação dos efeitos causados pelos dois estados de tensão aos quais o material está sujeito.
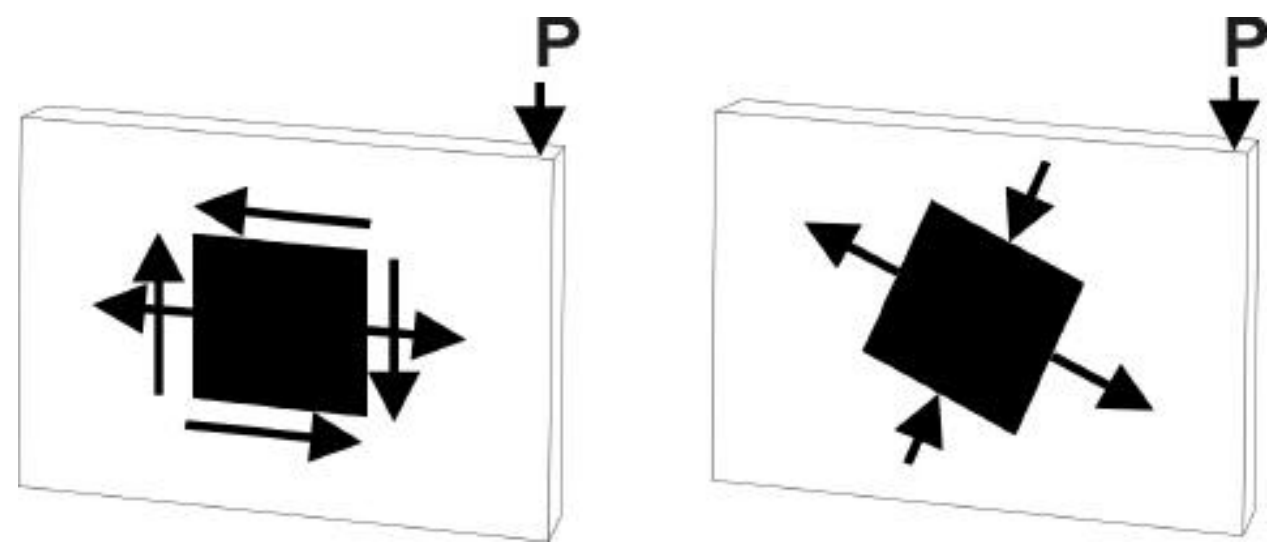

Figura 4 - Estado bi-axial das tensões. 
No estado tri-axial de tensões, o equilíbrio dar-se-á no espaço tridimensional, e uma ampliação do critério de resistência deve conter as três tensões principais normais que solicitam o elemento (fig. 5).

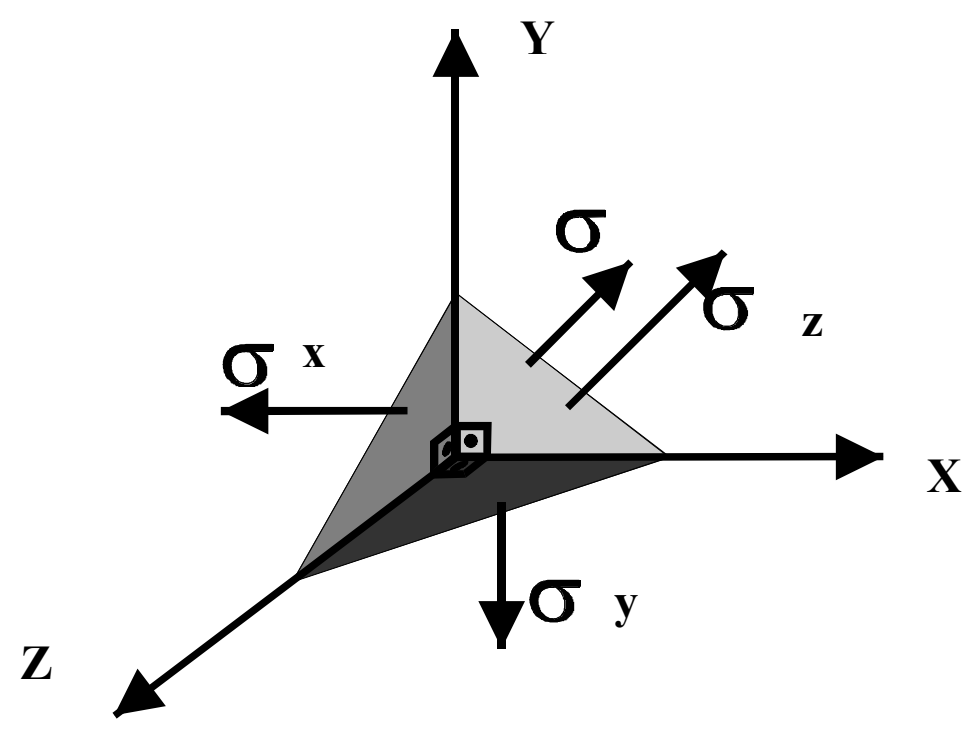

Figura 5 - Elemento sujeito ao estado tri-axial de tensões.

Uma forma de analisar conjuntamente todas as tensões que solicitam um elemento da malha é a utilização do critério das tensões principais (von Mises). Este critério baseia-se na energia de distorção de um determinado material, isto é, da energia relacionada com mudanças na forma do material (em oposição à energia relacionada com mudanças no volume). Por esse critério, um componente estrutural estará em condições de segurança, se o maior valor de energia de distorção por unidade de volume do material permanecer abaixo da sua energia de distorção, por unidade de volume. Saliente-se que as tensões de von Mises são sempre positivas e não é possível determinar se estas tensões são de compressão ou de tração. Sua vantagem é que, quando comparada com a tensão de escoamento do 
material, estabelece o grau de solicitação daquela região da estrutura. 0 programa de computador determinará as zonas de solicitação, segundo uma escala de cores correspondentes a cada faixa de tensão. 


\section{ANÁLISE E DISCUSSÃO DOS RESULTADOS}

Os retentores intra-radiculares são utilizados para conferir retenção em dentes tratados endodonticamente, o que já era utilizado por Harris em 1871. Outros autores buscaram aumentar a resistência dos dentes tratados endodonticamente (Sheets, 1970; Hirschfeld \& Stern, 1972; Colman, 1979). Kator \& Pines, 1977 e Davy et al., 1981 preocuparam-se com a distribuição de tensões para a raiz e osso alveolar. Para outros, a colocação de um retentor intra-radicular não aumentava a resistência da raiz (Trabert et al., 1978; Guzy \& Nichols, 1979; Trope et al., 1985). Essas diferentes opiniões têm causado controvérsias sobre 0 assunto.

Com a perda de fluidos dentinários, após o tratamento endodôntico, ocorre uma diminuição das propriedades físicas dos dentes, tornando-os mais susceptíveis àfraturas (Manning et al., 1995). Portanto, a confecção de um retentor intra-radicular deve seguir alguns princípios para não concentrar tensões na raiz e tecidos de suporte. O comprimento do pino desempenha um papel importante na distribuição de tensões, pois quanto maior o pino, melhor a distribuição de tensões na raiz, devendo-se tomar o cuidado para não comprometer o selamento endodôntico, deixando de 4 a $5 \mathrm{~mm}$ de gutapercha no terço apical (Abdullah \& Mohamed, 1974; McKerracher, 1981; 
Pierrisnard et al., 1994a ; Deutsh et al., 1997). O pino deve estar inserido numa raiz com boa inserção óssea (Reinhardt et al., 1983). O preparo do conduto não deve ultrapassar $1 / 3$ do diâmetro da raiz (Trabert \& Cooney, 1984), preservando o máximo de estrutura dentária, tanto coronária quanto radicular, melhorando a resistência da raiz (Sorensen, 1988).

Segundo Hunt \& Gogarnoiu (1996), um retentor intra-radicular deve promover um adequado selamento entre o material do retentor e a superfície da raiz, devendo possuir um adequado comprimento e assentamento nas paredes do canal. Não deve provocar concentração de tensões na estrutura remanescente durante a preparação, inserção e função e possuir rigidez necessária, que não permita a fratura da raiz ou do próprio retentor. A porção coronária do retentor deve ser resistente o bastante para resistir às forças mastigatórias e estar sustentada por estrutura dentária, tendo como resultado o efeito de cintamento, estando concorde com Morgano (1996); Morgano \& Brackett (1999), assim como Isidor et al. (1999), que acreditavam que o comprimento da cinta coronária era mais importante que o comprimento do pino, em uma análise de resistência àfratura.

Outra preocupação dos autores é com o formato dos retentores intraradiculares e como estes interferem na distribuição de tensões para a raiz e tecidos de suporte. Um retentor intra-radicular ideal seria aquele que obtivesse o máximo de retenção e que, durante o seu preparo, desgastasse o mínimo de estrutura dentária, transmitindo tensões de maneira uniforme ao remanescente dental. A preocupação inicial dos autores era com a retenção dos pinos (Stern \& Hirschfeld, 1973). Os pinos cilíndricos mostravam uma 
retenção 4,5 vezes maior que os pinos cônicos (Johnson \& Sakumura, 1973), além de distribuirem melhor as cargas, quando comparados ao desenho cônico, pois provocaram um efeito de cunha na raiz (Standle et al.,1972; Henry,1977;Spangler, 1980; Turner, 1982; Sorensen \& Engelman, 1990).

Lambjerg-Hansen \& Amusen (1997) priorizaram a estabilidade e não apenas a retenção dos pinos. Defenderam pinos com a porção coronária cilíndrica e apical cônica, o que também foi defendido por Pao et al. (1987). Estes autores demonstraram que a terminação cônica reduziu as tensões na dentina, além de ser mais conservadora em relação às estruturas da região apical, motivo pelo qual, também se resolveu estudar um pino com um formato cilíndrico e escalonado com a porção apical arredondada, que não necessita de preenchimento na porção coronária. 
Tensões no modelo com retentor intra-radicular cilíndrico e escalonado

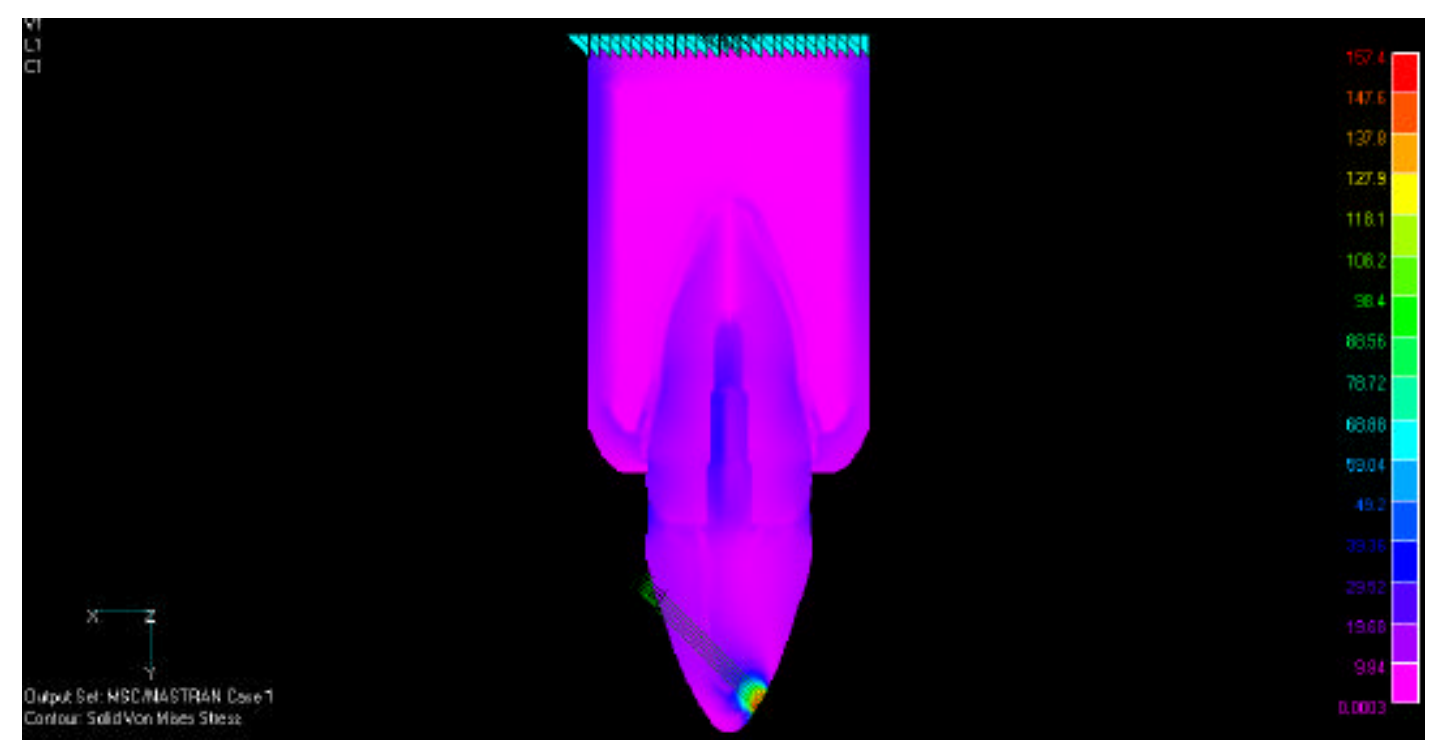

Fig 6 - Distribuição de tensões de von Mises, nas estruturas internas de um dente restaurado com coroa metalo-cerâmica, retentor intra-radicular cilíndrico e escalonado e nas estruturas de suporte.

A Figura 6 mostra a vista de um corte áxio-vestíbulo-lingual, que passa pela região de aplicação de carga, e os resultados da distribuição de tensões de von Mises, no modelo com retentor intra-radicular préfabricado escalonado. Verificou-se que as maiores tensões estão localizadas no ponto de aplicação de carga (157,4 Mpa ), na face palatina da coroa, a $2 \mathrm{~mm}$ da ponta de cúspide, dissipando-se, de forma radial, para as porções internas da coroa metalo-cerâmica, cimento fosfato de zinco, retentor intra-radicular, dentina e base óssea, conforme Hirshfeld \& Stern, 1972, sendo semelhante às observadas por Tresher \& Saito, 1973; Mori, 1994; Veiga, 1996; Vasconcellos, 1988. Concentrações menores de tensões de von Mises localizaram-se na margem vestibular e palatina da 
coroa, dentre estas, as maiores na vestibular, o que também foi encontrado por Ho et al., 1994 e Saldivar Bocangel, 1999. Yetran et al., 1996, mostraram a tendência de rotação da coroa, no ponto de apoio ou fulcro na sua margem vestibular e uma concentração de tensões de tração na margem palatina, podendo causar um defeito entre a coroa e a superfície da raiz, levando à desintegração do cimento e à infiltração marginal (Mitchell \& Kennedy, 1992), justificando assim, a não utilização de materiais de preenchimento com baixo módulo de elasticidade (Cohen et al., 1996; Pierrisnard et al., 1994b; Vasconcelos, 1998; Martines-Insua, 1998 e Borget \& Boston, 2000).

Pode também ser observada uma concentração de tensões na porção radicular, por vestibular do pino, no seu terço médio, entre o segundo e terceiro degrau. Essas tensões na porção mediana do pino, provavelmente representam o seu centro de rotação (Standlee \& Caputo, 1988). Pequenas concentrações de tensões foram observadas na porção externa da raiz, na face vestibular e palatina, na região próxima àinserção cortical e na região próxima ao terceiro degrau do pino, onde se encontra uma região de estreitamento da raiz. 


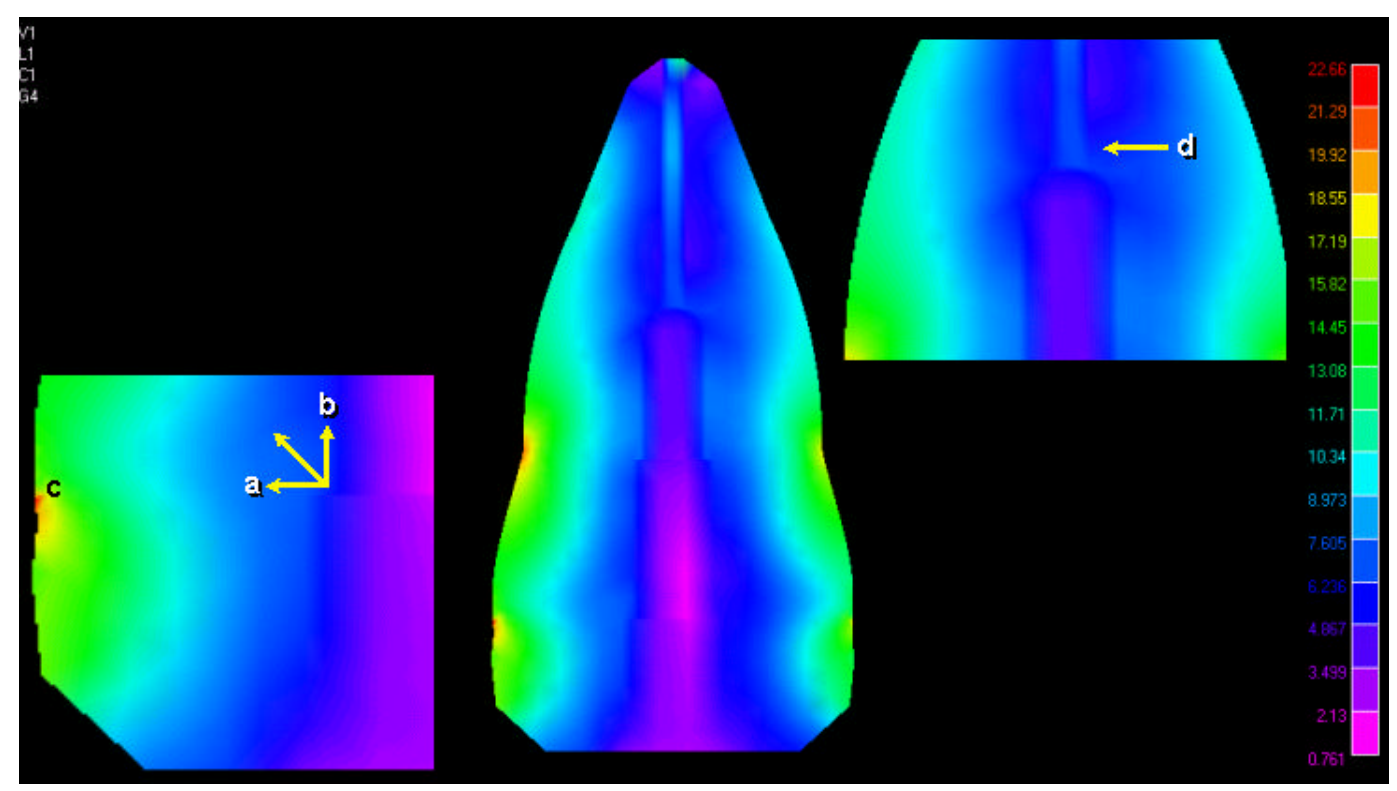

Figura 7 - Distribuição de tensões internas de von Mises, na dentina radicular do modelo 1. Detalhes: a) componente horizontal das tensões no $2^{\circ}$ degrau; b) tensões no sentido apical; c) somatória das tensões resultantes da deflexão do conjunto e do componente horizontal (a); d) baixa concentração de tensões no ápice.

Na figura 7, observa-se uma vista lateral de um corte áxio-vestíbulolingual da raiz, onde se pode analisar a distribuição de tensões na dentina do modelo 1. Nela, as maiores tensões concentraram-se, na superfície externa na face vestibular da raiz (22,66 Mpa ), na altura da crista óssea alveolar. Provavelmente, esta seria a região onde o dente se apoiaria no osso ao se deflexionar, gerando tensões sobre o remanescente dentário. Para Assif et al., 1989, esta corresponderia àregião de fulcro do conjunto. Já Cailleteau et al., 1992, acreditavam que a presença de um retentor intraradicular diminuiria as tensões na região cervical do dente, provavelmente pelo reforço estrutural, mudando o centro de rotação do conjunto mais para apical. Estes resultados estão de acordo com Ho et al., 1994 e Holmes et 
al.,1996, que, utilizando modelos tridimensionais, encontraram as maiores tensões no terço coronário da raiz. Ainda na figura 7 detalhe $c$, pode-se verificar o efeito da somatória da deflexão do conjunto, na região de crista óssea, mais a ação do componente horizontal resultantes do segundo degrau do pino (fig. 7 detalhe a), podendo explicar esta maior concentração de tensões na região coronária da raiz.

Uma grande concentração de tensões também foi encontrada na face vestibular, no terço médio da raiz, região onde existe um estreitamento na anatomia radicular, concorde com o trabalho de Hunter et al., 1989. A somatória com o componente horizontal do terceiro degrau gerou as maiores tensões em torno de 21,29 Mpa e uma área mais ampla, variando de 17,19 a 19,92 Mpa.

Concentrações menores de tensões localizaram-se na superfície externa da face palatina da raiz, na mesma altura onde ocorreram as maiores tensões por vestibular e uma pequena concentração de tensões no ápice da raiz, provavelmente resultantes da deflexão do conjunto dente/ retentor intra-radicular. A maior concentração das tensões, para o lado vestibular, provavelmente poderá ser contornada clinicamente, posicionando-se a broca mais para lingual dos dentes superiores, preservando-se a vestibular, conforme recomendações de Rosemberg \& Antonoff, 1971.

Na região apical do pino, houve baixa concentração de tensões de von Mises, provavelmente, devido ao formato escalonado, que propiciou a distribuição das tensões pelos degraus do pino. 
A escolha do cimento de fosfato de zinco foi baseada em trabalhos como os de Morgano, 1996; Morgano \& Bracket, 1999, que afirmaram que nenhum cimento possui propriedades físicas que compensem pinos mal desenhados, como pinos curtos, mal adaptados e combinados com uma coroa que não promova o efeito de cintamento. Daí, entende-se que, quando as propriedades biomecânicas dos retentores intra-radiculares são respeitadas, cimentos convencionais (fosfato de zinco) são o agente de selamento de preferência.

A análise do cimento de fosfato de zinco, utilizado tanto para a cimentação do retentor intra-radicular, como da coroa metalo-cerâmica, é mostrada pela figura 8 .

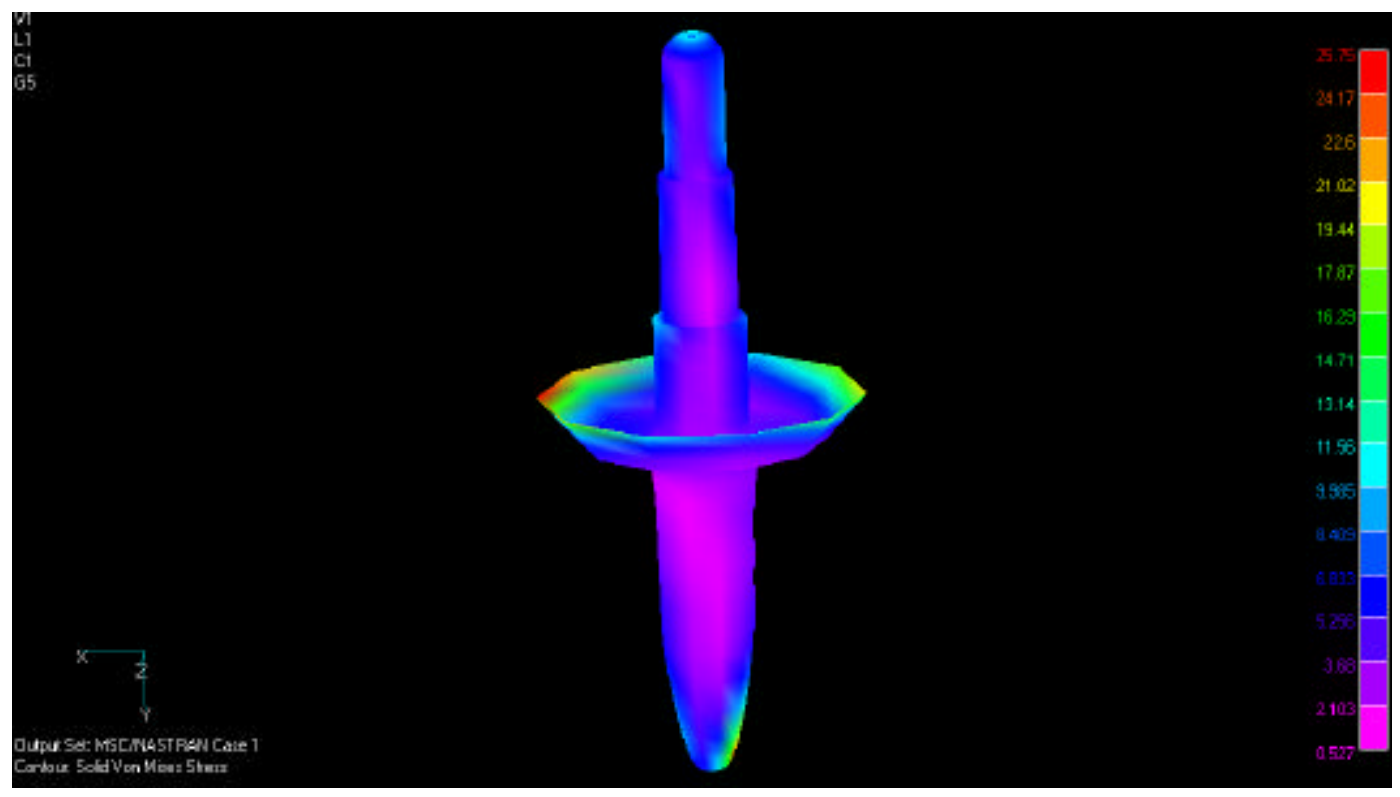

Figura 8 - Vista tridimensional da distribuição das tensões na película de cimento fosfato de zinco do modelo 1. 
A figura 8 mostra um aspecto extremamente interessante na distribuição de tensões da película do cimento de fosfato de zinco, no modelo 1. Nela, as maiores tensões se concentraram na região correspondente à margem vestibular da coroa, no bisel da linha de terminação (25,75 Mpa). Concentrações menores de tensões ocorreram na margem palatina da coroa, variando de 21,02 a 22,06 Mpa, resultantes da tendência de rotação da coroa, concordes com os trabalhos de Yetran et al., 1976 e Mitchell \& Kennedy, 1992, onde a região vestibular seria o fulcro da coroa, estando sujeita a tensões de compressão e a superfície palatina, à tensões de tração. Estas tensões na união entre a restauração e a dentina poderiam ocasionar falha no cimento (Farah \& Craig, 1974).

Concentração de tensões, também se localizaram no cimento próximo ao ponto de aplicação de carga, e estiveram na faixa entre 22,06 e 24,17 Mpa. Pequenas concentrações de tensões também ocorreram na face vestibular, na região correspondente ao segundo degrau do pino, que se encontra na altura da crista óssea alveolar, onde, segundo Assif et al., 1989, seria o ponto de fulcro do conjunto e nesta análise deve ser somada a resultante da dissipação de tensões do segundo degrau. Outra região que apresentou uma pequena concentração de tensões foi a região apical do cimento. Para Cailleteau et al., 1992, a camada de cimento tem uma importância fundamental, pois impede a transmissão direta de tensões à dentina, tanto coronária quanto radicular. Este fenômeno deve ser minimizado, utilizando-se o comprimento e assentamento adequado do pino (Hunt \& Gogarnoiu, 1996). 


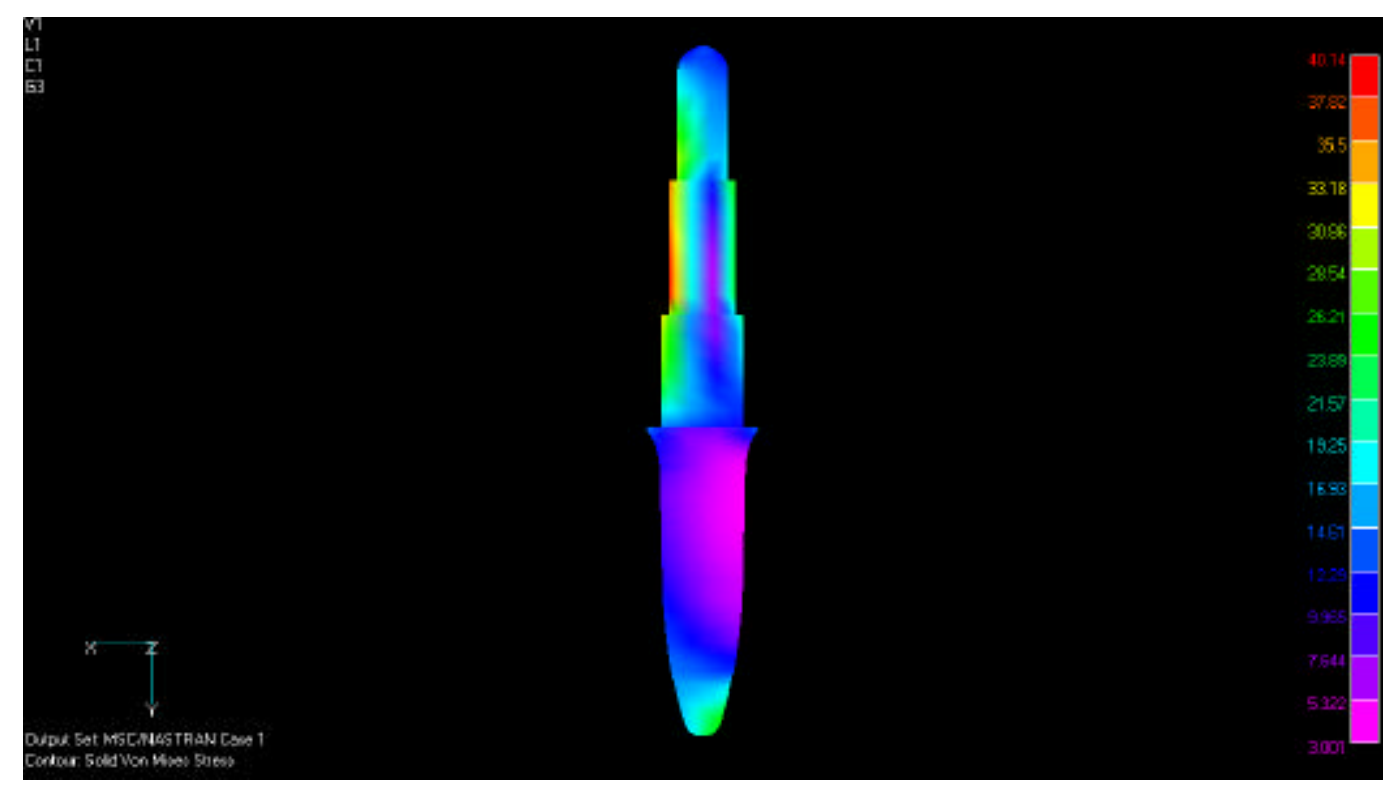

Figura 9 - Vista tridimensional da distribuição de tensões no retentor intra-radicular pré-fabricado cilíndrico e escalonado.

A figura 9 mostra a distribuição de tensões no retentor intraradicular escalonado. A maior concentração de tensões $(40,14 \mathrm{Mpa})$ ocorreu no terço médio da porção radicular por vestibular do pino, entre o segundo e terceiro degraus do retentor intra-radicular, limitados pelos próprios, que neutralizam as cargas progressivamente para apical. Diferentemente, os trabalhos de Davy et al., 1981 e Cailleteau et al., 1992, encontraram maiores tensões na região apical do pino, usando modelos bidimensionais. Esta diferença pode ser explicada pelo material que compõe o pino (titânio) e pela sua geometria (cilíndrico e escalonado). Também, por este ser um modelo tridimensional, sofreu menor deflexão que um modelo bidimensional, segundo Hunter et al., 1989.

As menores concentrações de tensões foram encontradas em uma grande área no terço médio e cervical, na região palatina do núcleo, e em 
uma área menor ligeiramente deslocada para palatino do pino, entre uma porção do primeiro degrau e parte inicial do terceiro, provavelmente pelo efeito da deflexão do pino dentro do conduto radicular.

\section{Tensões no modelo com retentor intra-radicular cônico}

Este modelo representou um dente com coroa metalo-cerâmica e um retentor intra-radicular de formato cônico, sendo, para Morgano,1996 o formato mais apropriado para retentores intra-radiculares, pois os pinos paralelos são mais retentivos, entretanto, necessitam de um maior desgaste dental para sua confecção. Além disso, o término em ângulo reto que concentra maiores tensões no terço apical da raiz, sendo preferíveis pinos ligeiramente cônicos, acompanhando a anatomia do canal radicular.

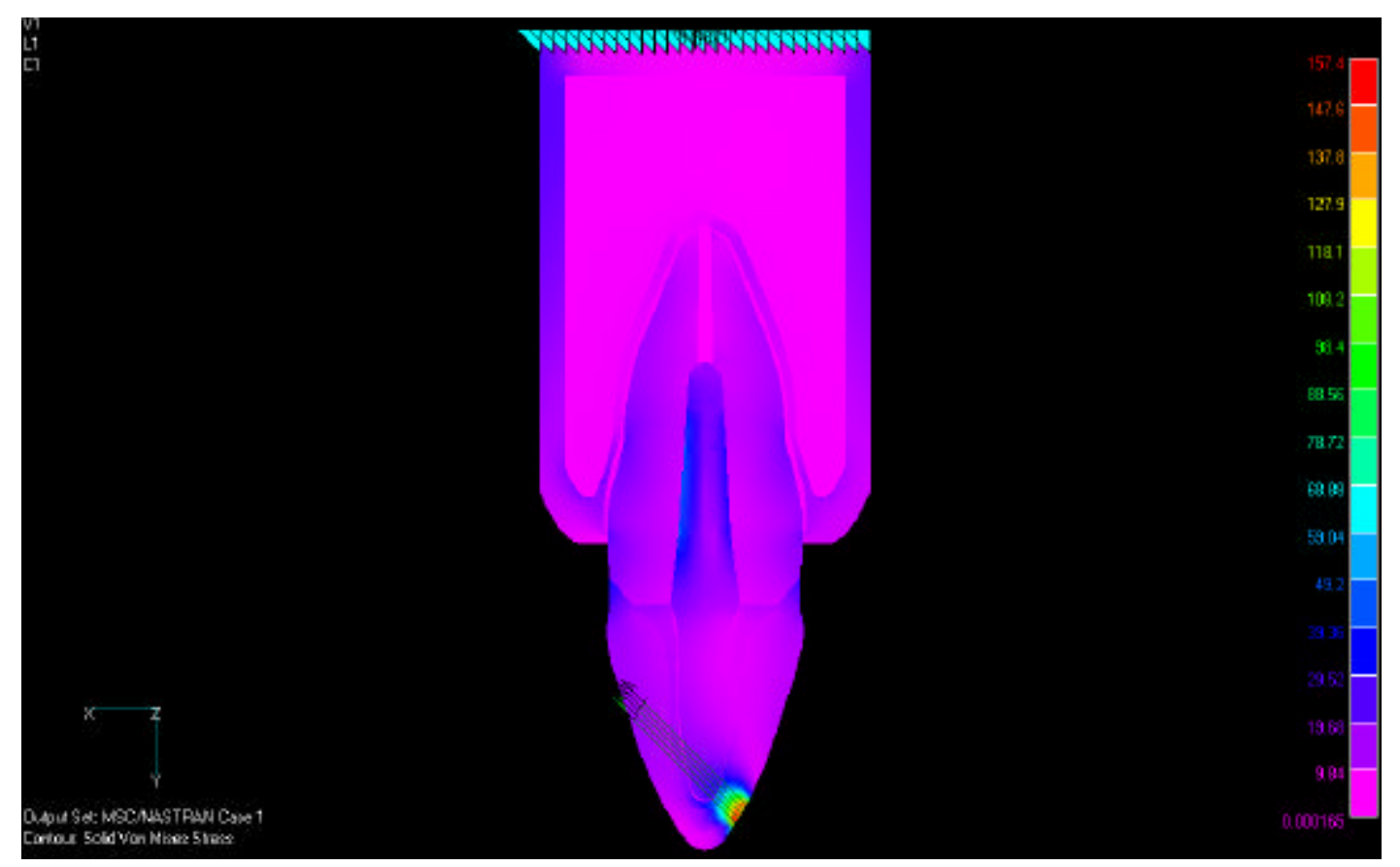

Figura 10 - Distribuição de tensões internas de von Mises, nas estruturas internas de um dente restaurado com coroa metalo-cerâmica, retentor intra-radicular cônico e nas estruturas de suporte. 
A figura 10 mostra a vista de um corte áxio-vestíbulo-lingual, que passa pela região de aplicação de carga, onde as mudanças realizadas deixaram o retentor intra-radicular cônico com o volume um pouco maior, mantendo-se o mesmo diâmetro, o que aumentou a concentração de tensões sobre ele, diminuindo as tensões sobre o remanescente dental (Hunter et al., 1989).

Assim como na figura 6, as maiores tensões concentraram-se no ponto de aplicação de carga com os mesmos valores de 157,4 Mpa, dissipando-se de forma radial para as porções internas da coroa metalocerâmica, cimento fosfato de zinco, retentor intra-radicular e base óssea. Estes mesmos valores, provavelmente se devem à utilização dos mesmos materiais e do mesmo formato para a confecção da coroa metalocerâmica.

Tensões menores também se concentraram nas margens da coroa, no bisel da linha de terminação, por vestibular e lingual, mostrando a tendência de rotação da coroa, semelhante ao encontrado na figura 6 .

Uma região de concentração de tensões, que se comportou diferente da encontrada na figura 6 , ocorreu no terço médio da porção radicular do pino por vestibular, correspondente ao seu centro de rotação (Standlee \& Caputo, 1988), onde foi observada uma maior concentração de tensões, porém, com uma distribuição mais uniforme que no retentor intraradicular escalonado, provavelmente, pela mudança da geometria do pino, para a forma cônica, deixando-o com maior volume, mais rígido, permitindo o maior acúmulo de tensões sobre ele, diminuindo a dissipação de tensões 
aos tecidos adjacentes, o que pode ser confirmado quando se observam as regiões de maior concentração de tensões na dentina, semelhantes às da figura 6 , porém, com tensões menores.

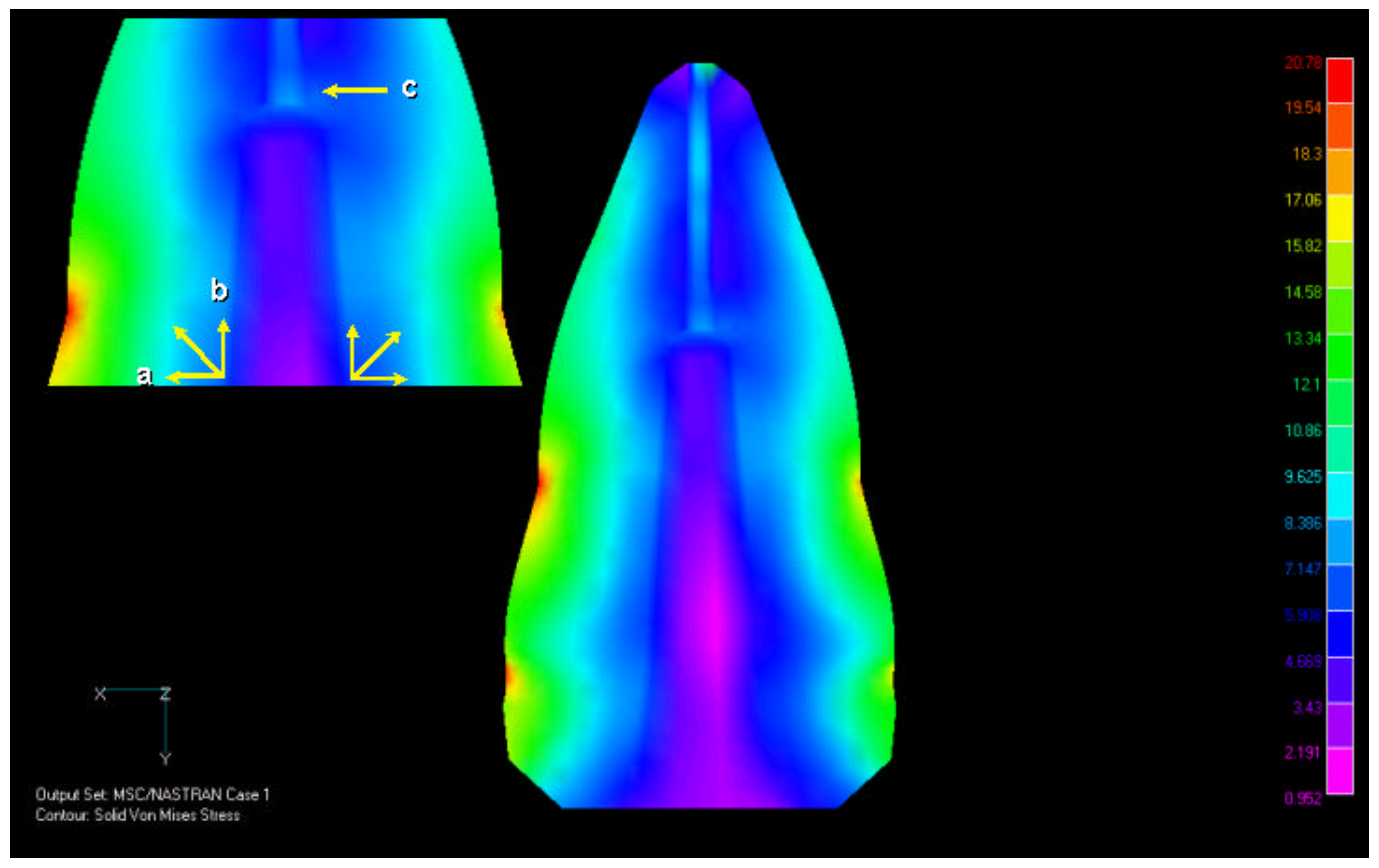

Figura 11 - Distribuição de tensões internas de von Mises, na dentina radicular do modelo 2. Detalhes: $a, b)$ distribuição de tensões ao longo do pino cônico; c) concentração de tensões no ápice.

A figura 11 representa a vista do corte áxio-vestíbulo-lingual da raiz, onde se pode analisar a distribuição de tensões na dentina do modelo 2. Nesta figura, as maiores tensões localizaram-se no terço médio da superfície externa da raiz por vestibular (20,78 Mpa), região onde ocorre um estreitamento da raiz, estando de acordo com Reinhardt et al., 1983 e Saldivar Bocangel, 1999, que utilizaram modelos bidimensionais e no terço coronário da raiz, na altura da crista óssea, no modelo 2 , onde ocorreu um acúmulo de tensões com os mesmos valores da região coronária da raiz, 
só que com uma área menor de concentração de tensões. Estas tensões na superfície externa, por vestibular da raiz foram $8,30 \%$ menores que na mesma região do modelo 1, estando de acordo com Ko et al., 1992, que utilizando o mesmo método com modelos tridimensionais encontraram uma grande concentração de tensões no terço médio e coronário da raiz. Na região vestíbular, no terço médio da raiz ocorreu um acúmulo de tensões 2,40\% menor, quando comparada àmesma região do modelo 1 .

Semelhantemente ao que foi encontrado na figura 6, concentrações menores de tensões localizaram-se na superfície externa, na face palatina da raiz, sendo tensões menores que as encontradas na raiz do modelo 1.

Outro aspecto importante é a baixa concentração de tensões no terço apical da raiz nos dois modelos, que se deve, provavelmente ao formato arredondado do ápice dos dois retentores intra-radiculares e pela preservação de estrutura dental no terço apical do retentor intra-radicular, respeitando a preocupação com o formato do ápice do pino (Reinhardt et al., 1983; Holmes et al., 1996) e com a preservação de estrutura dental no terço apical da raiz (Spangler, 1980 e Trabert \& Cooney, 1984). Entretanto houve uma concentração maior de tensões de von Mises no terço apical, principalmente no ápice do pino do modelo 2. No modelo 1, existe uma decomposição horizontal de tensões à partir dos degraus do pino, o que poderia explicar concentrações de tensões mais puntuais na superfície externa da raiz, concentrando menores tensões na sua região apical, enquanto no pino cônico, as cargas se dissiparam ao longo de todo o seu 
comprimento, porém com uma maior concentração de tensões no seu ápice.

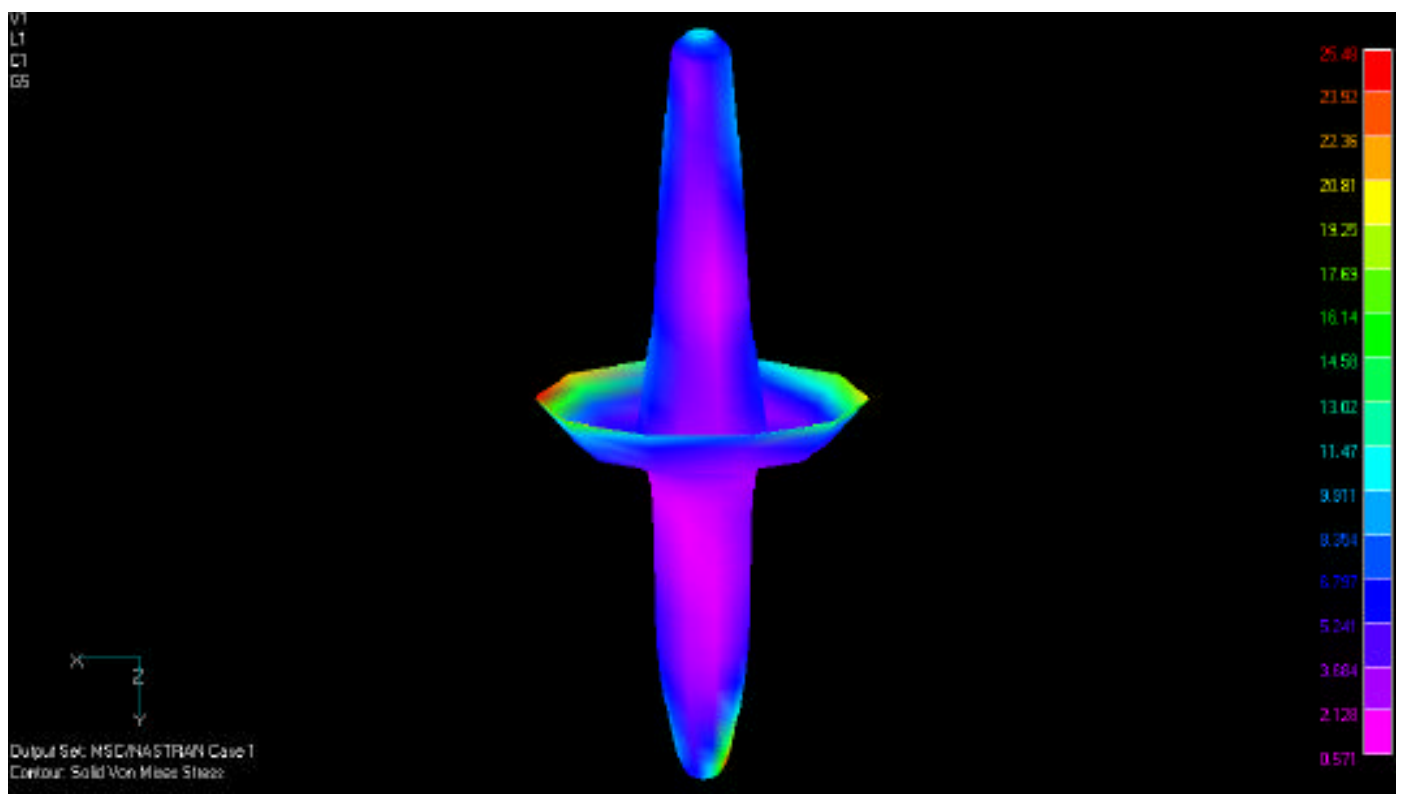

Figura 12 - Vista tridimensional da distribuição de tensões na película do cimento do modelo 2.

A figura 12 corresponde às tensões geradas na película de cimento de fosfato de zinco do modelo 2. Analisando a distribuição de tensões, observa-se uma situação bastante semelhante ao ocorrido no modelo 1. As maiores tensões também se concentraram na região vestibular, correspondente à margem da coroa, no bisel da linha de terminação (25,48 Mpa ), sendo apenas $1,05 \%$ menores que as tensões no modelo 1 . Concentrações menores de tensões, também ocorreram no bisel da margem palatina da coroa, com variação de 20,81 a 22,36 Mpa.

Na região próxima ao ponto de aplicação de carga, também existiu uma concentração de tensões, resultante da dissipação de tensões 
transmitidas pela coroa, com tensões na faixa de 22,36 a 23,92 Mpa, com uma distribuição de tensões tanto quantitativas como qualitativas muito próxima à encontrada na figura 8 do modelo 1, porém, sendo sempre menores, com menor tensão sobre a película de cimento fosfato de zinco.

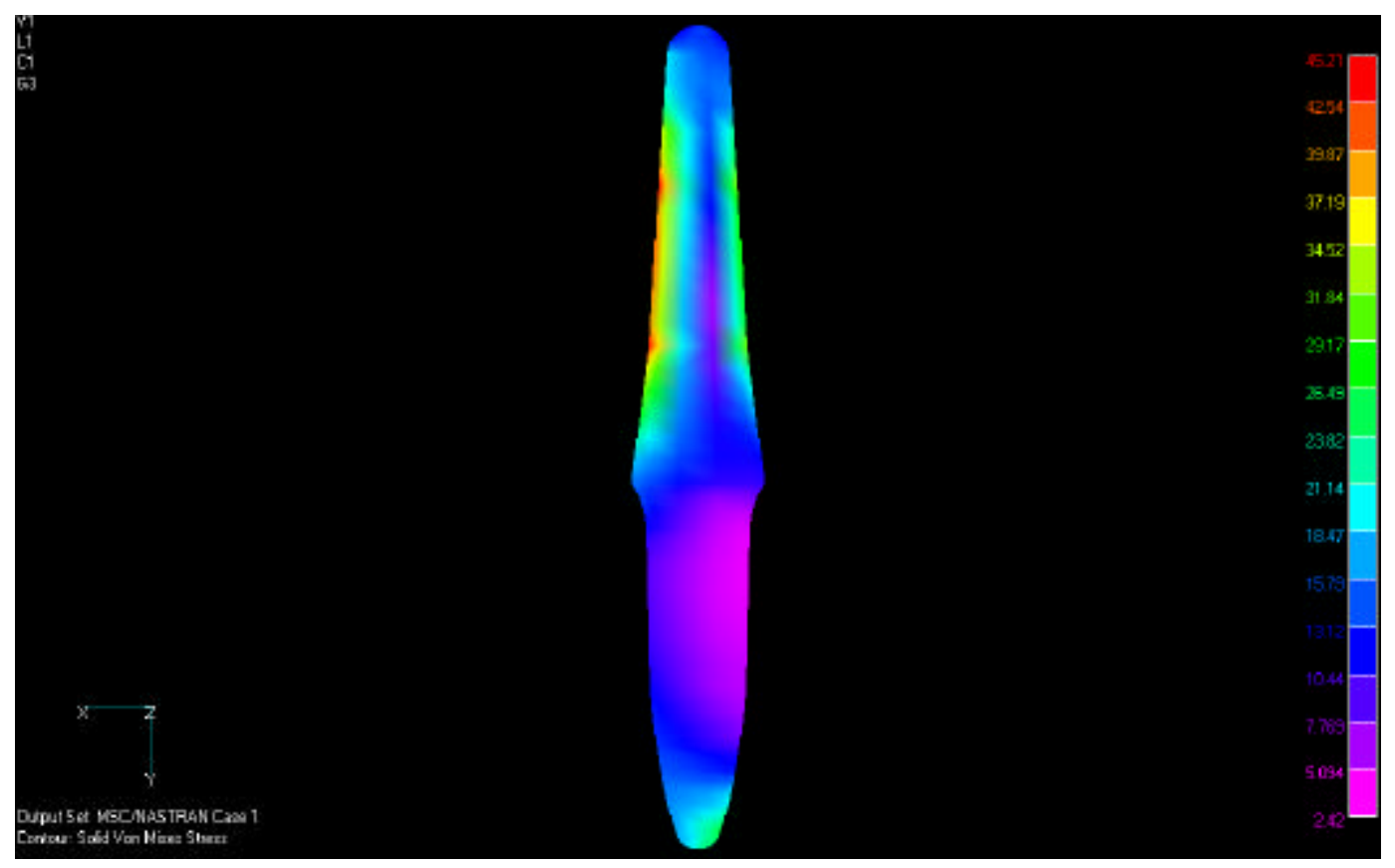

Figura 13 - Vista tridimensional da distribuição de tensões no retentor intraradicular cônico.

A figura 13 representa a vista tridimensional do retentor intraradicular com formato cônico. Nela, a maior concentração de tensões (45,21 Mpa) ocorreu por quase toda extensão da porção vestibular do pino, com concentrações maiores de tensões na altura da crista óssea e na região do centro de rotação do pino. Esses valores foram 11,22\% maiores que as maiores tensões encontradas no retentor intra-radicular escalonado. 
Nas regiões onde foram encontradas concentrações menores de tensões tanto na região coronária, como na região intra-radicular do pino, pode-se observar uma distribuição de tensões semelhante àencontrada no retentor intra-radicular escalonado. No entanto, essas tensões sempre foram maiores no de formato cônico.

A confecção de um retentor intra-radicular com um maior volume, criou uma estrutura mais rígida, concentrando mais tensões sobre ela e transmitindo menores tensões ao cimento fosfato de zinco e a raiz, concorde com o trabalho de Pierrisnard et al., 1995, que demonstraram que, quanto mais rigidez do pino, menor será a carga transmitida aos tecidos adjacentes.

Este aumento moderado no volume do retentor intra-radicular transmitiu menores as tensões ao cimento fosfato de zinco e ao remanescente dental, o que está de acordo com Hunter et al., 1989. No entanto não se deve esquecer os princípios de preservação de estrutura dentária, tanto coronária como radicular, no preparo do retentor intraradicular (Lloyd \& Palik, 1993 e Isidor et al., 1999), pois mesmo um pequeno aumento na concentração de tensões sobre uma raiz fragilizada, pode provocar uma fratura.

Os modelos 1 e 2 apresentaram comportamentos semelhantes e 0 ganho estrutural no modelo 2 apresentou certas vantagens sobre o modelo 1, quanto à distribuição de tensões na dentina e no cimento. No entanto, o formato cilíndrico e escalonado do pino pré-fabricado propiciou uma decomposição de tensões pelos seus degraus, dlstribuindo melhor as 
tensões a região apical do pino, enquanto o pino fundido cônico distribuiu mais as tensões ao longo do seu comprimento, porém, não causando uma maior concentração de tensões na região do ápice do pino, evidenciando o efeito de cunha.

O estudo teórico em modelos matemáticos pode dar uma previsão dos fenômenos biológicos que ocorrem em um corpo real. A metodologia de elementos finitos com modelos tridimensionais, mesmo axi-simétricos, traz inúmeras vantagens em relação a modelos bidimensionais, principalmente por permitir uma reprodução anatômica e forças de carregamento mais próximas do real (Vree et al., 1983; Rubin et al., 1983), embora o dente não apresente uma estrutura axi-simétrica. No entanto, Holmes et al., 1996 afirmaram que estruturas, tais como, dentes unirradiculares de forma ovalar, rententores intra-radiculares, implantes e blocos de osso podem ser descritas axi-simetricamente, apresentando resultados confiáveis. Novos estudos com modelos mais complexos e estudos clínicos devem ser realizados para confirmar ou questionar estes resultados. 


\section{CONCLUSÕES}

Os resultados obtidos, de acordo com a metodologia utilizada, nos permite concluir que:

1. Houve uma discreta diferença qualitativa e quantitativa quanto ao acúmulo de tensões de von Mises nos dois modelos. O pino escalonado neutralizou mais as cargas no sentido corono-apical e, no pino cônico, ficou evidenciado o efeito de cunha.

2. Na dentina radicular, as maiores tensões de von Mises ocorreram na região vestibular, no terço coronário do modelo 1 e no terço médio e coronário do modelo 2.

3. Nos dois modelos, as maiores tensões de von Mises, na película de cimento fosfato de zinco localizaram-se na região do bisel vestibular, sendo apenas $1,05 \%$ maiores no modelo 1. 


\section{REFERÊNCIAS BIBLIOGRÁFICAS ${ }^{*}$}

1. ABDULLAH, S.I.; MOHAMED, H.; THAYER, K.E. Restoration of endodontically treated teeth. A review. J Can Dent Assoc , v.40, n.4, p.300-303, Apr. 1974.

2. ASSIF, D.; OREN, E.; MARSHAK, B.L; AVIV, I. Photoelastic analysis of stress transfer by endodontically treated teeth to the suporting structure using different restorative techniques. J Prosthet Dent, v.61, n.5, p.535543, May 1989.

3. BEER, F.P.; JOHNSTON, E.R. Resistência dos materiais. 3. ed. São Paulo: Mc Graw Hill, 1999. 1255p.

"De acordo com NBR-6023 da Associação Brasileira de Normas Técnicas, 1989. Abreviatura de periódicos segundo "Index to Dental Literature". 
4. BORGERT, M.C.; BOSTON,D.W. Use of an existing post to rerestore an endodontically treated tooth with a new post-and-core complex and crown: A case report. Quintessence int, v.31, n.2, p.129-132, Feb. 2000.

5. CAILleteAU, J.; RIEGER, M.R.; AKIN, J. A comparison of intracanal stresses in a post-restored tooth utilizing the finite element method. $\mathbf{J}$ Endodo, v.18, n.11, p.540-544, Nov. 1982.

6. COHEN, B.I.; PAGNILLO, M.K.; CONDOS, S.; DEUTSCH, A.S. Four different core materials measured for fracture estrenght in combination with five differnt designs of endodontic posts. J Prosthet Dent. v.76, n.5, p.487-95, Nov. 1996.

7. COLMAN, H.L. Restoration of endodonticaly treated teeth. Dent Clin North Am, v.23, n.4, p.647-662, Oct. 1979.

8. DAVY, D.T.; DILLEY, G.L.; KREJCI, R.F. Determination of stress patterns in root-filled teeth incorporation various dowel designs. J Dent Res, v.60, n.7, p.1301-1310, July 1981 .

9. DELLA SERRA, O.; FERREIRA, F.V. Anatomia Dental. São Paulo. Artes Médicas, 3ª edição, p.100, 1981. 
10.DEUTSCH, A.; MUSIKANT, B.L.; COHEN, B.I. Rational predictable posthole preparation. Compendium, v.18, n.6, p.626-634, June 1977.

11. FARAH, J. W.; CRAIG, R. G. Finite element stress analysis of a restored axisymmetric first molar. J. Dent Res, v.53, n.4, p.859-866, July-Aug. 1974.

12. FRIEDMAN, C.; SANDRIK, J.; HEUER, M.; RAPP, G. Composition and mechanical properties of gutta- percha endodontic points. J Dent Res, v.54, n.8, p.921-925, Aug. 1975.

13. GRANT, D.; STERN, B.; EVERETT, F. Orban's periodontics: a concepttheory and practice. 4 ed. St Louis: CV Mosby, 1972.

14. GREENWALD, A.S. Cast gold and crown restoration. Dent Surv. v.41, n.4, p.47-50, April 1965.

15. GUZY, G.E.; NICHOLLS, J.I. In vitro comparison of intact endodontically treated teeth with and without endo-post reinforcement. J Prosthet Dent, v.42, n.1, p.39-44, July 1979.

16. HARRIS, C. The priciples and practice of dentistry. 10 ed. Filadelfia: Lindsay and Blakiston, 1871. 
17. HATZIKYRIAKOS, A. H.; REISIS, G. I.; TSINGOS, N. A 3-year postoperative clinical evaluation of posts and cores beneath existing crowns. J Prosthet Dent, v.67, n.4, p.454-458, Apr. 1992.

18. HENRY, P. J. Photoelastic analysis of post core restorations. Aust Dent J, v.22, n.3, p.157-164, June 1977.

19. HIRSCHFELD, Z.; STERN, N. Post and core - the biomechanical aspect. Aust Dent J, v.17, n.6, p.467-468, Dec. 1972.

20. HO, M.-H.; LEE, S.-Y.; CHEN, H.-H.; LEE, M.-C. Three dimensional finite element analysis of the effects of posts on stress distribution in dentin. $\mathbf{J}$ Prosthet Dent, v.72, n.4, p.367-372, Oct. 1994.

21. HOLMES, D.; DIAZ-ARNOLD, A.M.; LEARY, J.M. Influence of post dimensions on stress distribuition in dentin. J Prosthet Dent, v.75, n.2, p.140-147, Feb. 1996.

22. HUNT, P.; GOGARNOIU, D. Evolution of post dimensions on stress distribution in dentin. J Prosthet Dent, v.75, n.2, p.140-147, Feb. 1996. 
23. HUNTER, A.J.; FEIGLIN, B.; WILLIAMS, J.F. Effects of post placement on endodontically treated teeh. J. Prosthet Dent, v.62, n.2, p.166-172, Aug. 1989.

24. JOHNSON, J.K.; SAKUMURA, J.S. Dowel form and tensile force. J Prosthet Dent, v.40, n.6, p.645-649, Dec. 1978.

25. ISIDOR, F.; BRONDUM, K.; RAVNHOLT, G. The influence of post lenght and crown ferrule lenght on the resistance to ciclic loading of bovine teeth with prefabricated titanium posts. Int J prosth v.12, n.1, p.78-82, 1999.

26. KANTOR, M.E.; PINES, M.V. A comparative study of restorative techniques for pulpless teeth. J Prosthet Dent, v.38, n.4, p.405-412, Oct. 1977.

27. KO, C.-C.; CHU, C.-S.; CHUNG, K.-H.; LEE, M.-C. Effects of posts on dentin stress distribution in pulpless teeth. J Prosthet Dent, v.68, n.3, p.421-427, Sep. 1992.

28. LAMBJERG-HANSEN, H.; ASMUSSEN, E. Mechanical properties of endodontic posts. J Oral Reabil, v.24, n.12, p.882-887, Dec. 1997. 
29. LLOYD, P.; PALIK, J. The philosophies of dowel diamenter preparation: A literature review. J prosthet Dent, v.64, n.1, p.32-40, Jan. 1993.

30. MANNING, K. YU, D.; YU, H.; KWAN, E. Factors to consider for predictable post and core build-ups of endodontically treated teeth. Part I: Basic theorical concepts. Restorative Dent, v.61, n.8, p.685-695, Oct. 1995.

31. McKERRACHER, P.W. Rational restoration of endodontically treated teeth. I. Principles, techniques, and materials. Aust Dent J, v.26, n.4, p.205208, Aug. 1981.

32. MARTINEZ-INSUA, A.; DA SILVA, L.; RILO, B.; SANTANA, U. Comparisom of the fracture resistances of pulpless teeth restored wih a cast post and core or carbon-fiber post with a composite core. J Prosthet Dent v.80, n.5, p.527-532, Nov. 1999.

33. MILOT, P.; STEIN, R.S. Root fracture in endodontically treated teeth related to post selection and crown design. J Prosthet Dent, v.68, n.3, p.428434, Sep. 1992. 
34. MITCHELL, C.A.; ORR, J.F.; KENNEDY, J. A semi empirical model for prediction of how post-retained crowns will fail under compressive loading. J Dent Res, v.71, n.9, p.1613-1618, Sep. 1992.

35. MORI, M. Estudo da distribuição das tensões internas, em um dente natural e em dente restaurado com coroa metalocerâmica e retentor intra-radicular fundido, sob carga axial - método do elemento finito. São Paulo, 1994. 61p. Tese (doutorado) - Faculdade de Odontologia da Universidade de São Paulo.

36. MORGANO, S.M. Restoration of pulpless teeth: aplication of traditional principles in present and future contexts. J prosthet Dent, v. 75, n. 4, p. 375-380, April 1996.

37. MORGANO,S.M.; BRACKETT, S.E. Foundation restoration in fixed prosthodontics : current knowledge and future needs. J Prosthet Dent. v.82, n.6, p.643-57, Dec 1999.

38. MOROI, H.; OKIMOTO, K.; TERADA, Y. Numeric aproach to the biomechanical analysis thermam effects in coated implants. Int $\mathbf{J}$ Prosthod, v.6, n.9, p.564-572, Sept. 1993. 
39. MORRIS, H. F. Veterans administration cooperative studies project $n^{\circ}$ 147242. Part VII: The mechanical properties of metal ceramics alloys as cast and after simulated porcelain firing. J. Prosthet Dent v,61, n.2, p160-169, Feb. 1989.

40. MSC/NASTRAN for windows, reference manual, version 4.5. Los Angeles, MacNeal- Schwendler, 2000.

41. O, BRIEN, J. Dental materials and their selection. 2 ed. Chicago: Quintessence, 1997.

42. PAO, Y.C.; REINHARDT, R.A.; KREJCI, R.F. Root stress with tapered-end post desing in periodontally compromised teeth. J Prosthet Dent, v.57, n.3, p.281-286, Mar. 1987.

43. PIERRISNARD, L.; AUGEREAU, D.; DEGRANGE, M.; BARQUINS, M. Comportement mécanique des structures dentaires et osseuses. I. Influence de la longueur, du diamètre et du profil du tenon radiculaire, influence du support paradontal. Cah Proth, v.87, p.21-32, Sep. 1994. 
44. PIERRISNARD, L.; AugereAU, D.; DEGRANGE, M.; BARQUinS, M. Comportement mécanique des structures dentaires et osseuses. II. Analyse de la répartition des contraintes em fonction du type de reconstitution corono - radiculaire. Cah Proth, v.88, p.7-13, Dec. 1994.

45. PIERRISNARD, L.; AUGEREAU, D.; DEGRANGE, M.; BARQUINS, M. Comportement mecanique des structures dentaires et osseus. III. Influence du materiau constituant le tenon radiculaire. Cah Proth, v.89, p.7-14, Mars. 1995.

46. POWERS, J.M.; FARAH, J.W.; CRAIG, R.G. Modulus of elasticity and strength prosperties of dental cements. JADA, v.92, March. 1976.

47. REES, J.S.; JACOBSEN, P.H. Elastic modulus of the periodontal ligament. Biomaterials, v.18, n.14, p.995-100, July 1997.

48. REINHARDT, R.A.; KREJCI, R.F.; PAO, Y.C.; STANNART, J.G. Dentine stresses in post-reconstrected teeth with diminishing bone support. $\mathbf{J}$ Dent Res, v.62, n.9, p.1002-8, Sept. 1983.

49. ROSENBERG, P.A.; ANTONOFF, S.J. Gold posts - common problems in preparation and technique for fabrications. N Y State Dent J, v.37, n.10, p.601-606, Dec. 1971. 
50. RUBIN, C.; KRISHNAMURTHY, E.; CAPILOUTO, E.; YI, H. Sress analysis of the human tooth using a three-dimensional finite element model. $\mathbf{J}$ Dent Res, v.62, n.2, p.82-86, Feb. 1983.

51. SALDIVAR BOCANGEL, J.A.J. Estudo das tensões geradas em dentes íntegros e com tratamento endodôntico, restaurados com retentores intra-radiculares de diferentes mateiais e coroa total em porcelana. São Paulo, 1999, 93p. Dissertação (mestrado) - Faculdade de Odontologia da Universidade de São Paulo.

52. SANO, H.; CIUCCHI, B.; MATHEWS, W.G.; PASHLEY, D.H. Tensile properties of mineralized and demineralized human and bovine dentin. $\mathbf{J}$ Dent Res, v. 73, n.06, p.1205 -1211, June 1994.

53. SEGHI, R. R.; DENRY, I.; BRAJEVIC, F. Effects of exchange on hardness and fracture toughness of dental ceramics. Int J Prost, v. 5, N.4, p.309 314, Apr. 1992.

54. SHEETS, C.E. Dowel and core foundations. J prosthet Dent. v.23, n.1, p.58-65, Jane. 1970. 
55. SHILLIMBURG, H.T.; HOBO, S., WHITSETT, L.D. Fundamentos de Prótese Fixa, Chicago: Quintessence, P.78-79, 1988.

56. SMITH, C.T.; SCHUMAN, N. Restoration of endodontically treated teeth: a guide for the restorative dentist. Quint Int v.28, n.7, p.457-462, July 1997.

57. SORENSEN, J.A. Preservation of tooth structure. J Calif Dent Assoc, v.16, n.11, p.15-22, Nov. 1988.

58. SORENSEN, J.A.; MARTINOFF, J.T. Intracoronal reinforcement and coronal coverages: a study of endodontically treated teeth. $\mathbf{J}$ prosthet Dent. v.51, n.6, p.780-784, June 1984.

59. SORENSEN, J.A.; ENGELMAN, M.J. Effect of post adaptation on fracture resistance of endodontically treated teeth. J Prosthet Dent, v.64, n.4, p.419-424, Oct. 1990.

60. SPANGLER, C.C. Post and cores: some new ideas. Dent Surv, v.56, n.6, p.33-35, June 1980. 
61. STANDLEE, J.; CAPUTO, A.A. Biomechanics. J Calif Dent Assoc.), v.16, n.11, p.49-58, Nov. 1988.????

62. STERN, N.; HIRSHFELD, Z. Principles of preparing endodontically trated teeth for dowel and core restorations. J Prosthet Dent, v.30, n.2, p.162165, Aug. 1973.

63. THRESHER, R.W.; SAITO, G.E. The stress analysis of human teeth. J Biomech, v.6, n.5, p.443-449, Sep. 1973.

64. TRABERT, K.C.; CAPUT, A.A.; ABOU-RASS, M. Tooth fracture - A comparison of endodontic and restorative treatments. J Endod, v. 4, n. 11,p.341-345, Nov. 1978.

65. TRABERT, K.C.; COONEY, J.P. The endodontically treated tooth. Dent Clin North Am, v.28, n.4, p.923-951, Oct. 1984.

66. TROPE, M.; HALTZ, D.O.; TROSTAD, L. Resistance to fracture of restored endodontically treated teeth. Endod Dent Traumatol, v.1, p.108-111, 1985. 
67. TURNER, M.J.; CLOUGH, R.W.; MARTIN, H.C.; TOPP, L.J. Stiffness and deflection analysis of complex structures. J Aero Sci, v.23, n.9, p.805823, Sept. 1956.

68. TURNER, C.H. Post-retained crow failure: a survey. Dental Update, v. 9, n.4, p. 221-234, May. 1982.

69. VASCONCELLOS, A.B. Estudo das tensões internas em prótese parcial fixa, com dois sistemas de retenção corono-radicular: pinos préfabricados e retentores intra-radiculares fundidos - método dos elementos finitos. São Paulo, 1998. 76p. Tese (Mestrado) - Faculdade de Odontologia da Universidade de São Paulo.

70. VEIGA, J.A.L. Distribuição das tensões de von Mises em dente hígido e em dente restaurado com coroa metalo-cerâmica e retentor intraradicular fundido, sob carga axial e carga horizontal. São Paulo, 1996. 97p. Tese (Doutorado) - Faculdade de Odontologia da Universidade de São Paulo.

71. VREE, J.H.P.; PETERS, M.C.R.B.; PLASSCHAERT, A.J.M. A copararison of photoelastic and finite element analysis in restored tooth structures. $\mathbf{J}$ Oral Reabil, v.10, n.6, p.505-517, Nov. 1983. 
72. YAMAMOTO, M. Metal-ceramics. Chicago: Quintessence, p.429, 1985.

73. YETTRAN, A.L.; WRIGHT, K.W.J.; PICKARD, H.M. Finite element stress analysis of the crow of normal and restored teeth. J Dent Res, v.55, n.6, p. 1004-1011, Nov. 1976. 


\section{SUMMARY}

\section{FINITE ELEMENT ANALYSIS OF A ENDODONTICALLY TREATED TEETH RESTORED WITH TWO DIFFERENT TYPES OF POST AND CORE SYSTEMS}

The aim of this study was to compare the von Misses stress distribution on a human canine teeth endodontically treated and restored with two types of post and core. The analysis was made using the three dimensional Finite Element Analysis method. For the analysis was created and axy-simetric structure of the teeth, including a porcelain fused to metal crown, a cement layer, and the periodontal structures. The model was analyzed when a $100 \mathrm{~N}$ load was applied on the surface of the crown with $45^{\circ}$ angulation with the long axis of the teeth. The results showed that both models exhibit little difference, the "stair shape" post system neutralized the axial loads, and the conical shape post showed a wedge effect on the apical third of the root. 